\title{
A new method for improving the performance of an ionospheric model developed by multi-instrument measurements based on artificial neural network
}

\author{
Wang $\mathrm{Li}^{\mathrm{a}}{ }^{\mathrm{b}}$, Changyong $\mathrm{He}^{\mathrm{b}, \mathrm{c}}$, Andong $\mathrm{Hu}^{\mathrm{b}, \mathrm{d}}$, Dongsheng Zhao ${ }^{\mathrm{a}}$, Yi Shen ${ }^{\mathrm{e}}$, Kefei Zhang ${ }^{\mathrm{a}, \mathrm{b}, *}$ \\ ${ }^{a}$ School of Environmental Science and Spatial Informatics, China University of Mining and Technology, Xuzhou 221116, China \\ ${ }^{\mathrm{b}}$ SPACE Research Center, School of Science, RMIT University, Melbourne, VIC 3001, Australia \\ ${ }^{\mathrm{c}} I G N$, ENSG, Cité Descartes, Champs-sur-Marne, 77455 Marne la Vallée, France \\ d Multi-scale Group, Centrum Wiskunde \& Informatica (CWI), Science Park 123, 1098 XG Amsterdam, Netherlands \\ ${ }^{\mathrm{e}}$ Key Laboratory for Synergistic Prevention of Water and Soil Environmental Pollution, Xinyang Normal University, Xinyang 464000, China
}

Received 11 March 2020; received in revised form 24 July 2020; accepted 27 July 2020

\begin{abstract}
There are remarkable ionospheric discrepancies between space-borne (COSMIC) measurements and ground-based (ionosonde) observations, the discrepancies could decrease the accuracies of the ionospheric model developed by multi-source data seriously. To reduce the discrepancies between two observational systems, the peak frequency (foF2) and peak height (hmF2) derived from the COSMIC and ionosonde data are used to develop the ionospheric models by an artificial neural network (ANN) method, respectively. The averaged root-mean-square errors (RMSEs) of COSPF (COSMIC peak frequency model), COSPH (COSMIC peak height model), IONOPF (Ionosonde peak frequency model) and IONOPH (Ionosonde peak height model) are $0.58 \mathrm{MHz}, 19.59 \mathrm{~km}, 0.92 \mathrm{MHz}$ and $23.40 \mathrm{~km}$, respectively. The results indicate that the discrepancies between these models are dependent on universal time, geographic latitude and seasons. The peak frequencies measured by COSMIC are generally larger than ionosonde's observations in the nighttime or middle-latitudes with the amplitude of lower than $25 \%$, while the averaged peak height derived from COSMIC is smaller than ionosonde's data in the polar regions. The differences between ANN-based maps and references show that the discrepancies between two ionospheric detecting techniques are proportional to the intensity of solar radiation. Besides, a new method based on the ANN technique is proposed to reduce the discrepancies for improving ionospheric models developed by multiple measurements, the results indicate that the RMSEs of ANN models optimized by the method are 14-25\% lower than the models without the application of the method. Furthermore, the ionospheric model built by the multiple measurements with the application of the method is more powerful in capturing the ionospheric dynamic physics features, such as equatorial ionization, Weddell Sea, mid-latitude summer nighttime and winter anomalies. In conclusion, the new method is significant in improving the accuracy and physical characteristics of an ionospheric model based on multi-source observations.
\end{abstract}

(C) 2020 COSPAR. Published by Elsevier Ltd. All rights reserved.

Keywords: Artificial neural network; Ionospheric model; Data correction; COSMIC; Ionosonde

* Corresponding author at: School of Environmental Science and Spatial Informatics, China University of Mining and Technology, Xuzhou 221116, China.

E-mail address: profkzhang@cumt.edu.cn (K. Zhang).

\section{Introduction}

Ionospheric total electron content (TEC), peak frequency (foF2), peak electron density $(\mathrm{NmF} 2)$ and the corresponding peak height $(\mathrm{hmF} 2)$ of the $\mathrm{F} 2$ layer are 
important parameters to represent the ionospheric activity. The global or regional ionospheric models developed by these parameters play an important role in satellite navigation and physical mechanism explanation of ionospheric prominent temporal-spatial structures widely (Brum et al., 2011; Li et al., 2015; Themens et al., 2017; Zhang et al., 2014). Nowadays both space-borne and groundbased techniques could directly measure these critical ionospheric parameters, but each technique has its specific strengths and weaknesses. Ionosonde is the most popular traditional ground-based ionospheric measuring technique with a high temporal resolution ranges from $30 \mathrm{~s}$ to $5 \mathrm{~min}$. Due to the inhomogeneous distribution of land, the ground-based ionosonde isn't available to monitor the ionospheric dynamics over oceans. The recent rapid development of the Global Navigation Satellite Systems (GNSS) radio occultation (RO) technique opens doors to detect the three-dimensional structure of the ionospheric electron density, such as plasma bubbles (Bauer et al., 2014; Guo et al., 2019; Li et al., 2018b; Li et al., 2018c; Yue et al., 2014). The Constellation Observing System for Meteorology, Ionosphere and Climate (COSMIC) is the most powerful GNSSS RO system, which could collect about 2500 ionospheric density profiles daily. But the trajectories of the GNSS-RO electron density profiles are nonstationary. The Abel inversion is usually used to retrieve the ionospheric vertical electron density $(\mathrm{Ne})$ between GPS and low earth orbiting (LEO) satellite links. However, the assumption of spherical symmetry in the Abel retrieval often causes significant errors in the retrieved $\mathrm{Ne}(\mathrm{h})$ profiles, particularly at regions where large horizontal electron density gradients exist, such as the equatorial ionization anomaly (EIA) region and around dusk/dawn terminators (Ram et al., 2016).

In previous studies, much attention has been paid to investigate the discrepancies between multiple instruments. Lei et al. was first to validate the measurements between ionosonde, incoherent scatter radars (ISR) and COSMIC, and found that the COSMIC profiles were in agreement with the ionosonde and ISR measurements (Lei et al., 2007), while other studies reported that the peak parameters retrieved from COSMIC's measurements have an unneglectable discrepancy with ionosonde's observations over a single station or regional area. The peak parameters of COSMIC were validated by ionosonde's data over Sanya (Hu et al., 2014), the results indicated that the correlation coefficient of NmF2 between COSMIC and ionosonde was about 0.89 , and the coefficient for $h m F 2$ was 0.8 respectively. The correlation coefficient was also dependent on the intensity of solar activity. For example, in the nighttime, the NmF2 coefficient was higher than that in the daytime, but this case was opposite for hmF2.

The comparative results over a single station may contain many uncertainties, it is believed that the validations over a regional area may be more reliable, such as European region (Krankowski et al., 2011), Australia (McNamara and Thompson, 2015), Brazilian region
(Ely et al., 2012), China (Sun et al., 2014), etc. It has demonstrated that the COSMIC measurements were in a good agreement with ionosonde observations in the middle latitudes of European regions, the absolute standard deviations of discrepancies were $1.78 \times 10^{4} \mathrm{el} / \mathrm{cm}^{3}$ for $\mathrm{NmF} 2$ and $11.46 \mathrm{~km}$ for $\mathrm{hmF} 2$, and the corresponding ratios were $8.42 \%$ and $4.89 \%$, respectively (Krankowski et al., 2011). In Australia, the standard deviation of $\mathrm{hmF} 2$ discrepancies exceeded $42 \mathrm{~km}$, in particular, the discrepancy over the Vanimo station located in the southern crest of the equatorial ionization anomaly (EIA) was much larger than that in the middle latitudes (McNamara and Thompson, 2015). Especially in the geomagnetic equator trough near the Brazilian region, this phenomenon was more evident. In the Cachoeira Paulista region alongside the trough, the results indicated that the correlation coefficient for $\mathrm{NmF} 2$ was 0.92 , while the correlation coefficient for hmF2 was only 0.69 , a trans-equatorial wind or electron density gradients were speculated to be the factors contribute for the differences (Ely et al., 2012). The global statistical validation results demonstrated that the peak densities measured by COSMIC were systematically smaller than ionosonde's observations, and the amplitude of discrepancy in the low and high latitudes was more remarkable ( $\mathrm{Chu}$ et al., 2010). Also, the results confirmed that the peak height measured by COSMIC was systematically higher than ionosonde's values, which was not consistent with the studies over the Brazilian region. A lot of studies conclude that the discrepancy between the two techniques can be as large as $20 \%$ or more in equatorial regions, and the magnitude of discrepancy was inversely proportional to the fluctuations of electron density profiles. The unneglectable discrepancy between multiple instruments is an important factor affecting the performance of ionospheric model based on multiple measurements. However, nowadays the nonlinear discrepancies are still cannot be corrected by any mathematic functions.

The artificial neural network (ANN) has a powerful ability to solve the multivariable nonlinear problems by systematic learning mechanisms, and it has been applied to develop the ionospheric models successfully (Sai Gowtam and Tulasi Ram, 2017a; Song et al., 2018). Gowtam et al. (2019), Tulasi Ram et al. (2018) have used the long-term ionospheric observations to develop the artificial neural network-based global two/three-dimensional ionospheric model (ANNIM, ANNIM-3D), the ionospheric profiles derived from ANN models were found to be consistent with the ground-based incoherent scatter radar observations. In addition, these models successfully capture the prominent large-scale ionospheric phenomena, such as the diurnal and seasonal variations of equatorial ionization anomaly, ionospheric annual anomaly (Rishbeth et al., 2000), and the ionospheric trough. The powerful performance of ANN models has also been verified in Li et al.'s study ( $\mathrm{Li}$ et al., 2020), the accuracies of foF2 and hmF2 models built by ANN technique were $20-30 \%$ higher than the International Reference 
Ionosphere (IRI) model, and the ANN models present a good capability to reproduce the global or regional ionospheric spatial-temporal characteristics. The above literatures demonstrate that the ANN technique could successfully extract the multivariable nonlinear relationship between ionospheric parameters and geographic location, solar-geomagnetic indices, thermospheric winds, etc. Therefore, the ANN method maybe a useful tool in correcting the significant discrepancies between multiple instruments and improving the performance of ionospheric models established by multi-source measurements. Hence, this paper is structured as follows. The data measured by COSMIC and ionosonde are used to develop global ionospheric models for predicting foF 2 and $\mathrm{hmF} 2$, respectively. The discrepancies between these models are discussed on universal time, season, and geographic latitude. Besides, a new method based on ANN algorithm is proposed to correct the remarkable discrepancies, then the "mixed" corrected data (original observations and corrected measurements) are used to build a new global ionospheric model. Furthermore, some prominent regional ionospheric anomalies are validated to evaluate the physical characteristics of the ionospheric model.

\section{Data and methodology}

\subsection{Data}

The joint Taiwan-United States FORMOSAT-3/ COSMIC mission was the first satellite constellation dedicated to remotely sense Earth's atmosphere and ionosphere using a technique called Global Positioning System (GPS) radio occultation (Yue et al., 2014), it was launched into orbit by the United States Air Force (USAF) from Vandenberg on 15 April 2006. This constellation consisted of six microsatellites around $800 \mathrm{~km}$ circular orbits, after 2014 this constellation gradually stopped working. In the study, the $10.7 \mathrm{~cm}$ solar flux, COSMIC electron density profiles and ionosonde's observations in the data range set of 2007.01 to 2016.12 are selected, see Fig. 1. Fig. 1(a) shows the daily averaged $10.7 \mathrm{~cm}$ solar flux from 2007 to 2016, the solar flux is provided by the Space Physics Data Facility of NASA (https://omniweb.gsfc.nasa.gov/). In 2006-2010, the solar radiation was at a low level, and it increased dramatically from 2011 and reached to the maximum intensity with 250SFU in 2014-2015. Fig. 1(b) and (c) are the monthly averaged numbers of COSMIC's profiles and ionosonde's observations in the entire data range. The COSMIC profiles and ionosonde data are obtained from the University Corporation for Atmospheric Research (UCAR) community programs (https://www.cosmic.ucar.edu/) and Digital Ionogram Data Base (http://giro.uml.edu/didbase/scaled.php). During 20082011, the FORMOST-3/COSMIC constellation could collect about 2500 profiles per day, afterward, the electron density profile amount gradually decreased with the breakdown of the low-orbit microsatellite. However, the number of ionosonde's observations steadily increased in the entire data range with the increment of ionosonde stations. The spatial distributions of daily COSMIC events and the global ionosondes selected in this study are shown in Fig. 2, and the daily COSMIC events are selected on spring equinox, 2009.

In the data preprocessing stage, all the samples must be checked for quality control, in Fig. 1(b) and (c), the cyan and purple bars represent the total measurements and the qualified measurements. For COSMIC profiles, the ionospheric electron density profiles between GPS and LEO links can span across several longitudes and latitudes, the peak parameters of individual COSMIC RO profiles vary from the peak values that derived from vertical profiles at the locations of the peak parameters, this phenomenon is more remarkable in the profiles with a wide spatial span. To reduce the errors, the COSMIC profiles with latitude spans larger than $10^{\circ}$ or longitude spans larger than $15^{\circ}$ were removed in the quality control stage (Okoh et al., 2019). Then the passed profiles were fitted by Chapman- $\alpha$ function (Bilitza et al., 2006), and the correlation coefficients between the measured profiles and fitted profiles were computed. The measured profiles with the correlation coefficient of lower than 0.85 were eliminated in the quality control process. It is also noted that the COSMIC profiles contain the Abel-inversion errors, the systematic errors were not removed in the study. For ionosonde data, the observations exceeded the bounds determined by mean \pm 1.5 times standard deviation were removed (Potula et al., 2011). After the process of quality control, the rate of qualified samples was about $85 \%$.

\subsection{Artificial neural networks}

The neural network theory was first proposed by the McCulloch and Pitts (1943), the adaptive linear neuron approach was introduced by Widrow and Hoff (1960) in the 1960s, which improved the learning ability of neural networks greatly. With the developments of the backpropagation of errors and adapting learning rate in the feed-forward neural networks, the study ability and learning rate of the neural network had greatly improved.

In this study, a feedforward neural network consisting of three hidden layers was adopted to develop the ionospheric models with COSMIC's profiles and ionosonde's observations, respectively. The architecture of this neural network is shown in Fig. 3. In the input layer, the input parameters contained four kinds of parameters, they were time, geographic location, solar activity, and geomagnetic activity. The time parameters consisted of DOY (day of year), UT (universal time). The location parameters were formed by Mlat (geomagnetic latitude) and Lon (geographic longitude). Solar activity parameters consisted of sunspot number (SSN), F10.7 (10.7 cm solar flux), Vsw (solar wind speed). Geomagnetic indices included Dst, Kp and Ap. Once the input parameters were determined, 70\%, 15\% and $15 \%$ of the total data set were randomly chosen as the 


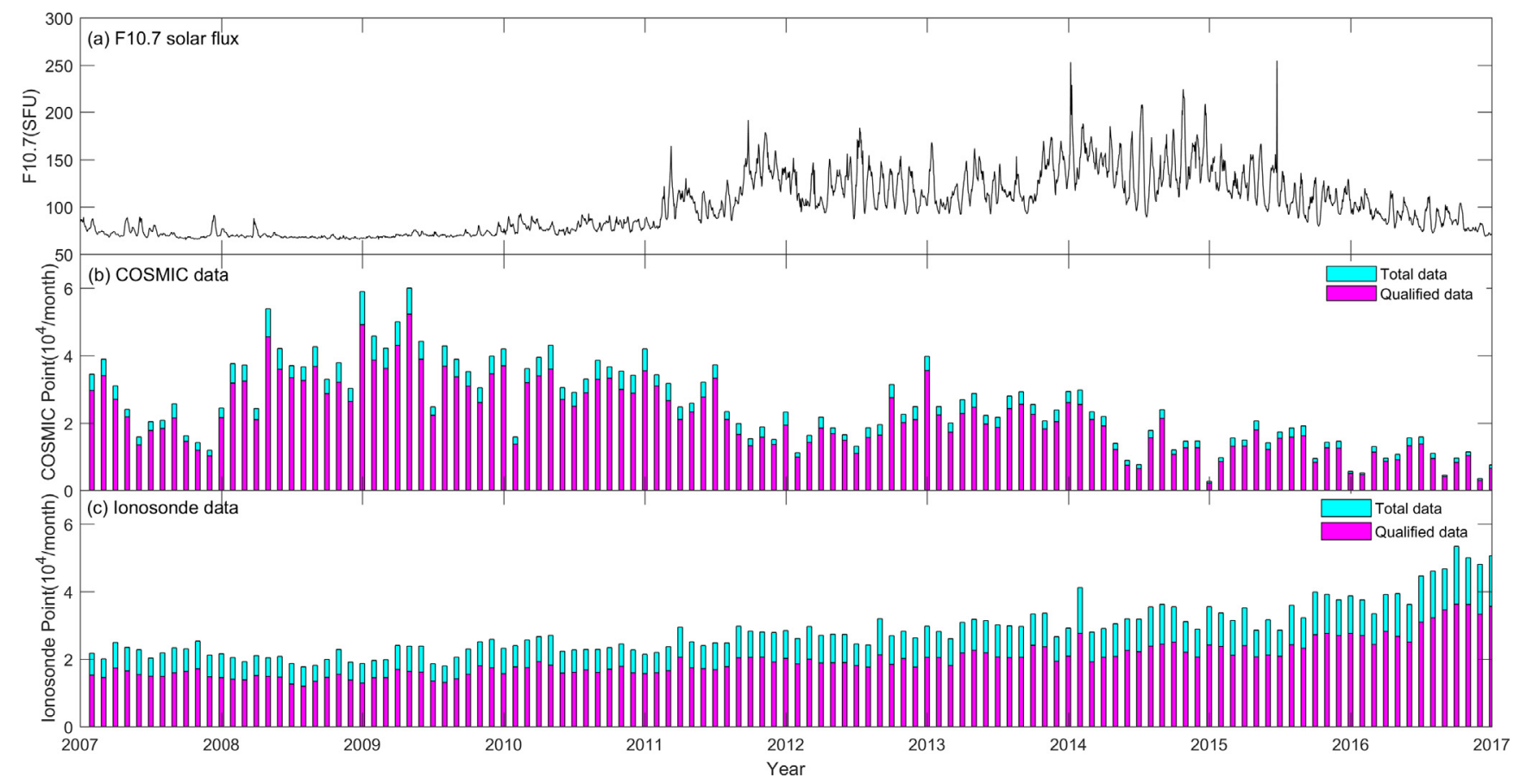

Fig. 1. F10.7 solar flux, COSMIC electron density profiles and ionosonde's measurements during 2007-2016.

(a) COSMIC profiles

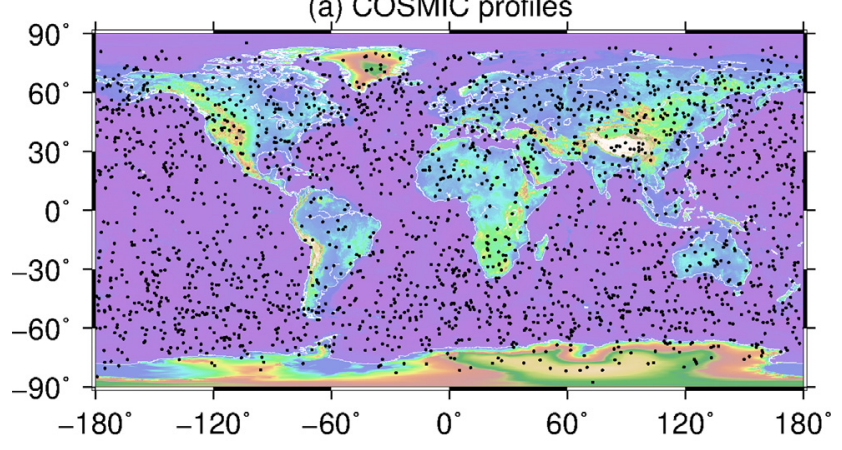

(b) lonosonde stations

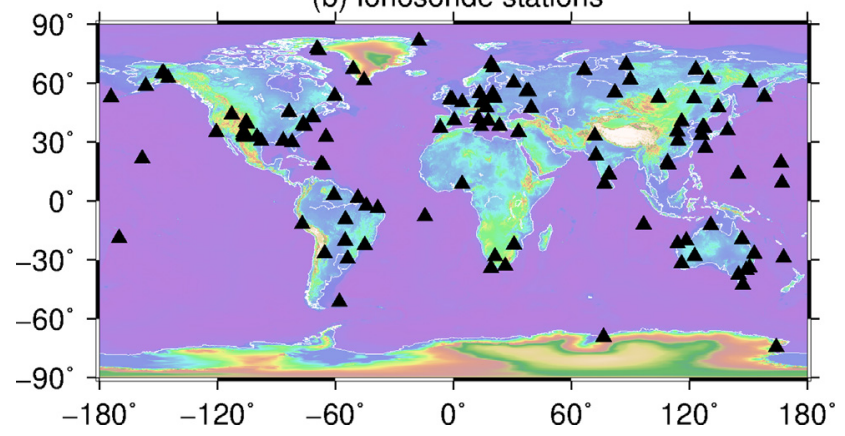

Fig. 2. Spatial distributions of daily COSMIC events and global ionosondes.

training set, validation set, and test set. Because the sample was numerous exceeding 10 million points, a deep neural network (three hidden layers) was used to develop the ionospheric models. Though some theories reported that a shallow network (single hidden network) with enough nodes could capture any complex nonlinear relationships, our experiments show that a deep neural network can improve the learning efficiency than a shallow network remarkably. The average period of linear regressions performed by a deep neural network was $28.6 \mathrm{~min}$, while the averaged linear regression performed by a shallow network took about $39.2 \mathrm{~min}$. The comparative results indicated that the learning efficiency of linear regression performed by a deep network improved $27 \%$ than a shallow network. The tansig, tansig and sigmoid activation functions were used in the three hidden layers, respectively. For more details about the activation functions, the readers are referred to Specht's study (Specht, 1990). Hundreds of experiments indicated that the mean square error (MSE) of the neural network was minimized when the neurons in three hidden layers were 16, 14 and 12, respectively (Li et al., 2020). In this study, both COSMIC's profiles and ionosonde's observations were utilized to build global ionospheric models for predicting foF2 and hmF2 based on the neural network's architecture, respectively. These models were named as COSMIC peak frequency (COSPF), COSMIC peak height (COSPH), ionosonde peak frequency (IONOPF) and ionosonde peak height (IONOPH). It is noted that the ionospheric peak frequency (foF2) cannot be measured directly by the GNSS radio occultation, but the NmF2 and foF 2 can be transformed by

$N m F 2=1.24 \times 10^{10} \times(f o F 2)^{2}$

To evaluate the performances of four models, the COSMIC/ionosonde measurements and the model's simulations were compared by a linear regression (bold line), the comparisons were shown in Fig. 4. The regression coefficients (R) and root-mean-square error (RMSE) between 


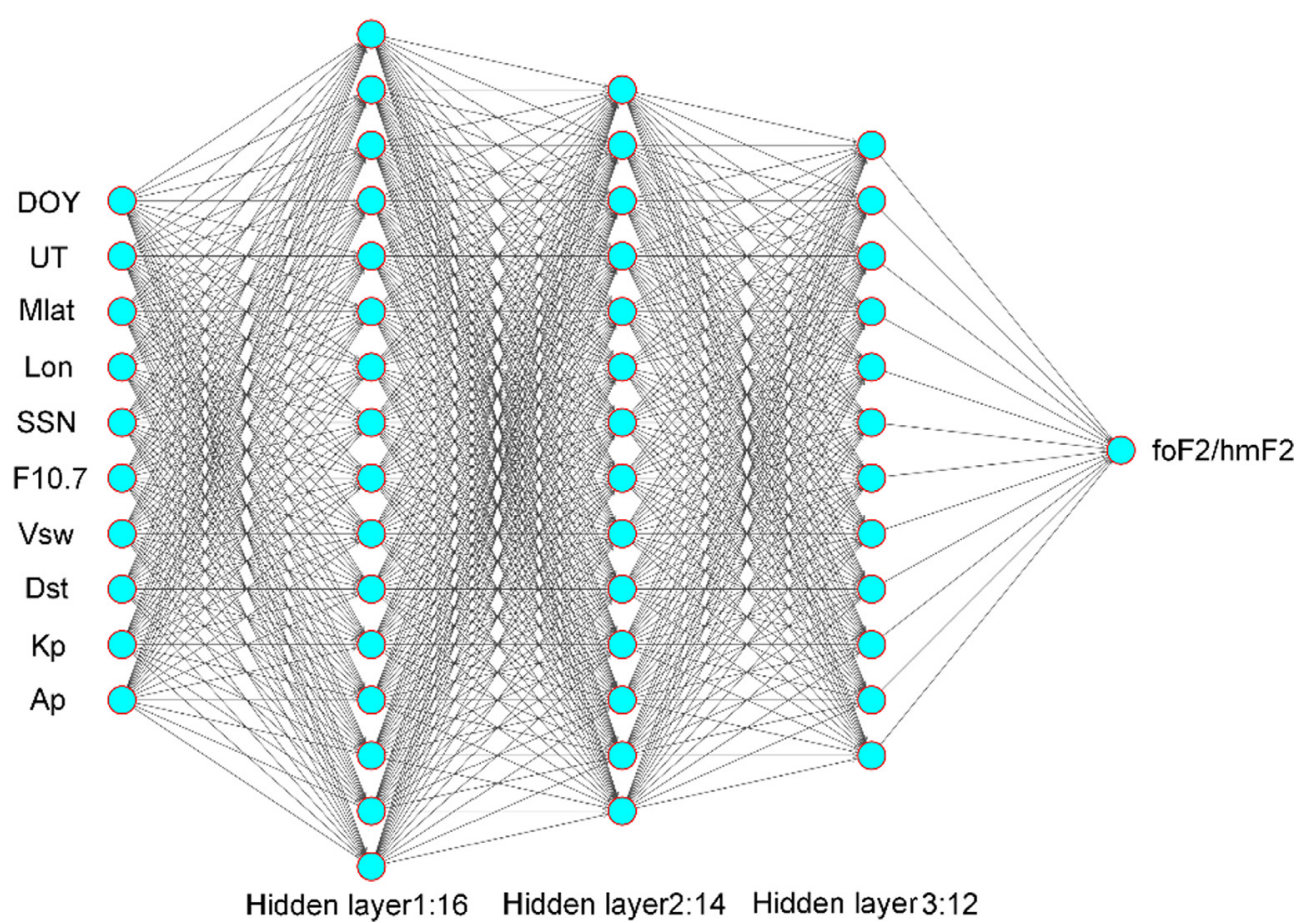

Hidden layer1:16 Hidden layer2:14 Hidden layer 3:12

Fig. 3. Structure of the artificial neural network used in the study.

observations and simulations were used to evaluate the simulated performances of the ANN models. Generally, the simulated performances of the model developed by COSMIC's profiles were better than that based on ionosonde's data. For example, the regression coefficient between the foF 2 values measured by COSMIC and the values simulated by the COSPF model was 0.97 , the RMSE of the COSPF model was $0.58 \mathrm{MHz}$; while the R coefficient and RMSE between ionosonde's foF2 values and IONOPF's simulated values were 0.92 and $0.92 \mathrm{MHz}$, respectively. The RMSE of the IONOPF model was 59\% larger than that of the COSPF model. This conclusion was also applied to hmF2. The $\mathrm{R}$ coefficient and RMSE for the COSPH model were 0.92 and $19.59 \mathrm{~km}$, but the coefficient and RMSE for the IONOPH model were 0.80 and $23.40 \mathrm{~km}$, respectively. The simulated performance of the IONOPH model was $19.4 \%$ worse than that of the COSPH model. The comparative results indicated that the accuracies of ANN models using same structures were different, the accuracies of ionospheric models based on COSMIC RO profiles were much higher than that built by ionosonde points. Therefore, the performance of ionospheric model developed by multi-measurements would be reduced if the remarkable discrepancies were not removed in the quality control stage.

\section{Results}

\subsection{Validation of the discrepancy in latitude}

Due to the fact that the observations of COSMIC and ionosonde are not distributed uniformly on a global scale as same as the global ionospheric map (GIM), it is difficult to systematically evaluate the discrepancies between COSMIC and ionosonde dependent on geographic locations, seasons, solar-geomagnetic activities, etc. In this study, our strategy was to simulate the grid maps of foF 2 and $\mathrm{hmF} 2$ by the ANN models and to investigate the differences between COSMIC's maps and ionosonde's maps in different universal time, latitudinal zones and solar activities. The weekly foF 2 grid maps were simulated by the COSPF and IONOPF model at the moments of UT00, UT06, UT12 and UT18 from 2007 to 2015, and the corresponding averaged foF 2 time series were estimated in the low, middle and high latitudinal zones, the comparative results were shown in Fig. 5. Meanwhile, the mean values of the foF2 time series during 2007-2015 simulated by COSPF and IONOPF were also calculated, and the ratio of the discrepancy between two-time series was computed as follows

Ratio $=\frac{\text { CosMean }- \text { IonoMean }}{\text { CosMean }} \times 100 \%$

where CosMean is the mean value of the foF2 time series simulated by the COSPF model, and IonoMean is the mean value for the IONOPF model.

Generally, there were remarkable discrepancies between the averaged foF 2 time series simulated by COSPF and IONOPF, and the discrepancies changed with the universal time, geographic latitude. In the low latitudes, the foF 2 values simulated by IONOPF model were higher than COSPF's foF2 in the nighttime with the ratio of 4.61$21.2 \%$, see Fig. 5(a) and (b); while in the day time, the COSPF's foF2 gradually increased and exceeded the IONOPF's value, see Fig. 5(c) and (d). Especially in the dusk, the positive ratio was $23.88 \%$. However, the foF 2 
(a) COSMIC-foF2

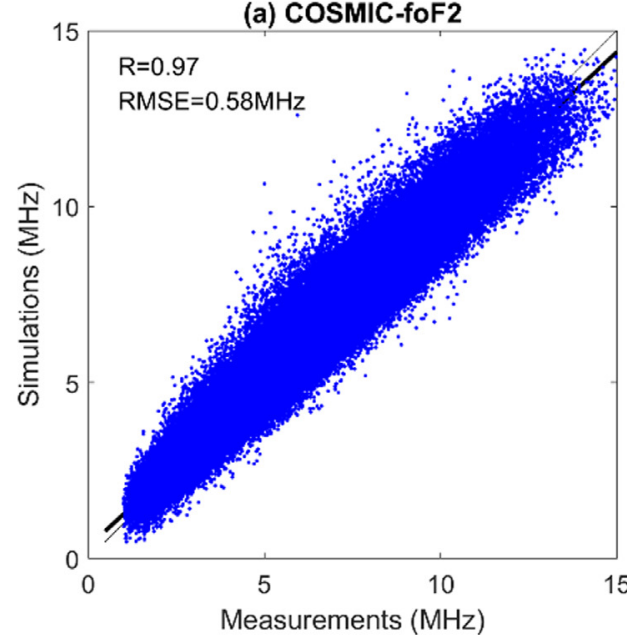

(c) COSMIC-hmF2

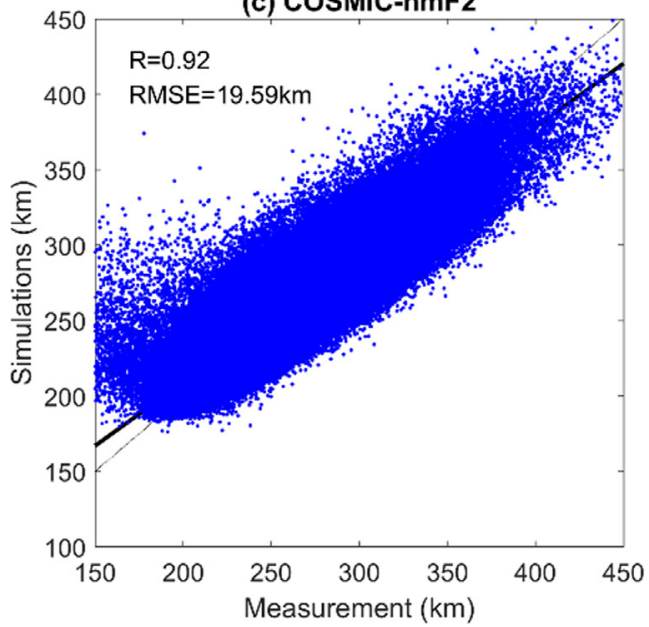

(b) lonosonde-foF2

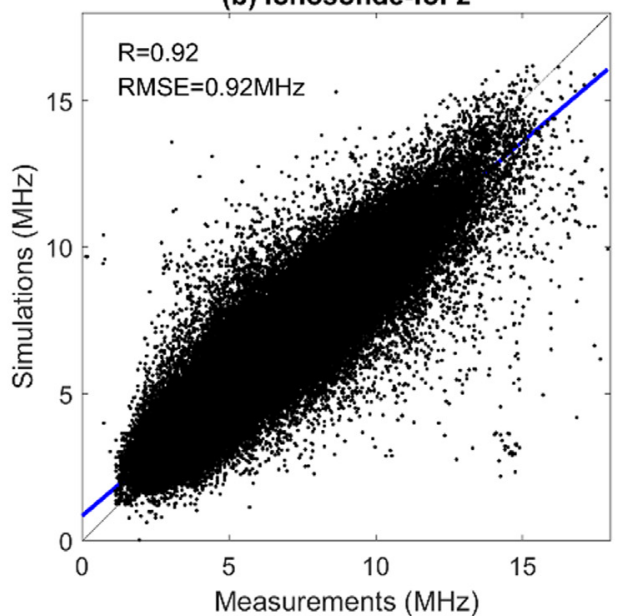

(d) lonosonde-hmF2

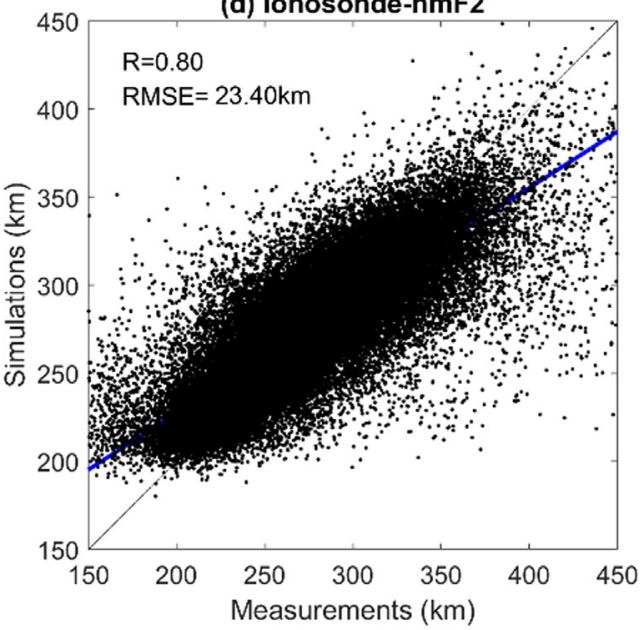

Fig. 4. Line regression between the target parameters and simulated values of (a) COSPF, (b) IONOPF, (c) COSPH and (d) IONOPH.

time series in the middle and high latitudes weren't in agreement with the phenomenon in the low latitudinal zone. From the middle row of Fig. 5, it was found that the foF 2 values derived from the COSPF model were always larger than that of the IONOPF, and the amplitude of discrepancies was more remarkable in the nighttime. In the polar regions, the result was as same as that in the middle latitudes with a ratio of small than $20 \%$.

In conclusion, there were significant discrepancies between the observations of COSMIC radio occultation and ground-based ionosonde with a maximum ratio of $25 \%$. The discrepancies were dependent on universal time and geographic latitude significantly, especially in the nighttime and middle latitudes, the amplitude of discrepancy was maximum. But for years, the dependent relationship was not remarkable.

Same as foF2, the discrepancies between the hmF2 time series simulated by COSPH and IONOPH model were also remarkably. In the low latitudes, the COSPH's hmF2 values were larger than that simulated by the IONOPF model generally. Especially in the midnight and dusk (Fig. 6(a) and (d)), the ratio of the discrepancy was within $7-14 \%$. Different from the phenomenon in the low latitudinal zone, the bottom row of Fig. 6 showed in the polar region the IONOPH's simulations were significantly higher than the COSPH. In the noon and dusk (Fig. 6(k) and (i)), the averaged amplitude of discrepancy exceeded $30 \mathrm{~km}$ with the ratio of about $-12 \%$. However, the discrepancies between multiple measurements weren't remarkable in the middle latitudes. From Fig. 6(e) to (h), it was found that the $\mathrm{hmF} 2$ measured by COSMIC was roughly equal to the ionosonde's products, the maximum averaged amplitude of the discrepancy was about $10 \mathrm{~km}$ with the ratio of $4.22 \%$. This conclusion was opposite to the results for foF2 in the same latitude zone.

In conclusion, the $\mathrm{hmF} 2$ discrepancies between spaceborne COSMIC radio occultation and ground-based ionosonde cannot be neglected, and the discrepancies were more significant in the low-high latitudes during daytime with a maximum amplitude of $30-50 \mathrm{~km}$, which was consistent with previous studies (Ely et al., 2012).

\subsection{Validation of the discrepancies globally}

Section 3.1 has demonstrated that there were remarkable discrepancies between COSMIC and ionosonde 

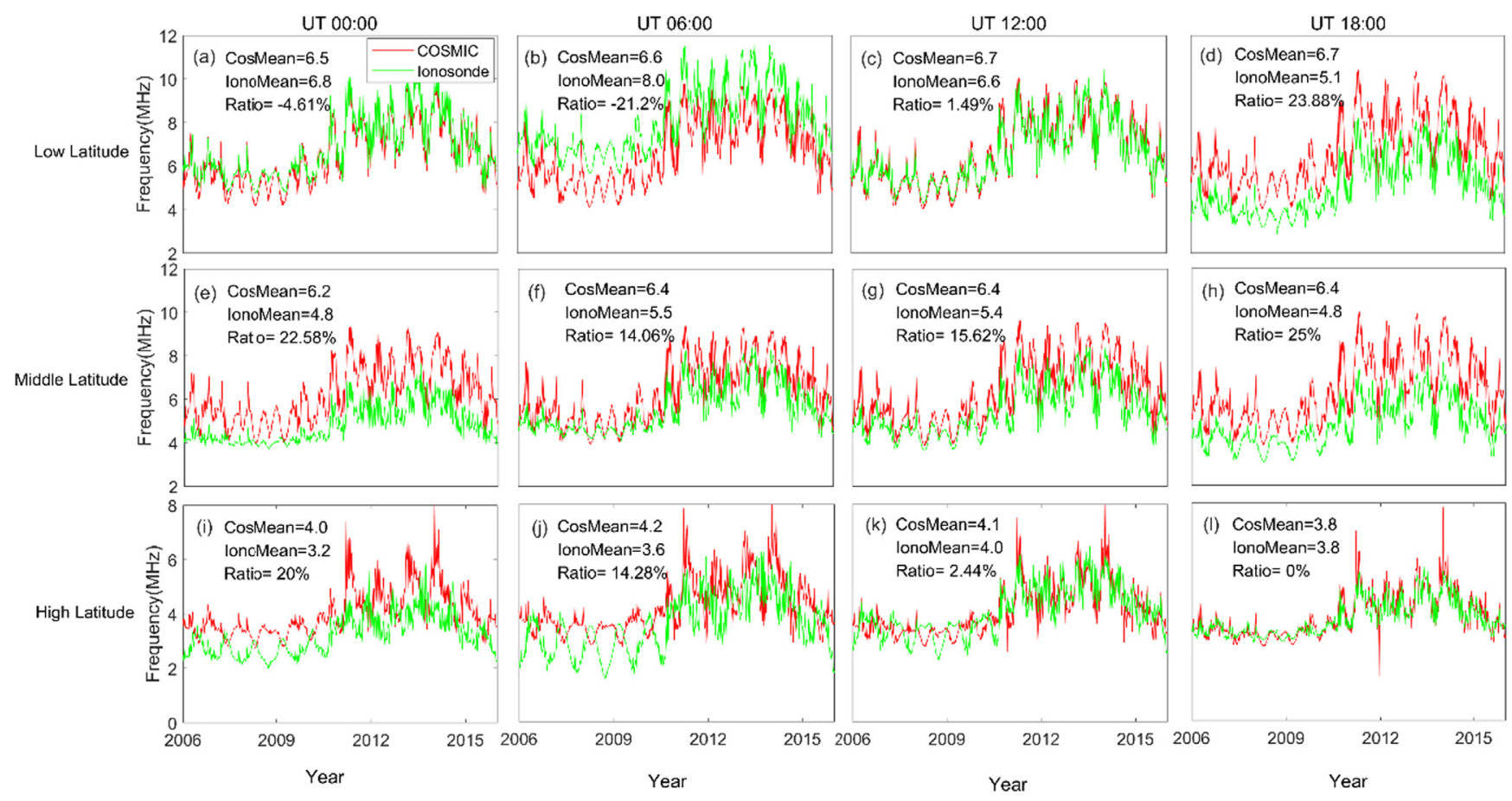

Fig. 5. Averaged foF2 time series simulated by the COSPF and IONOPF model in low, middle and high latitudinal zones.

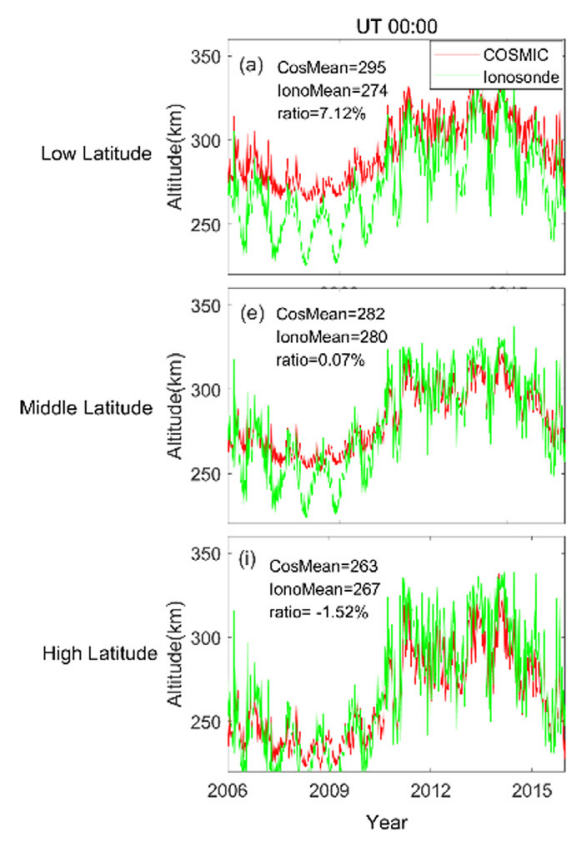

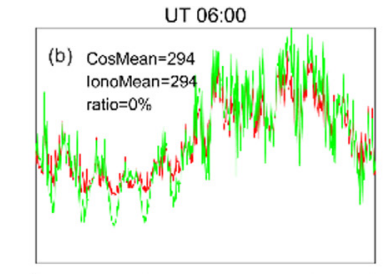
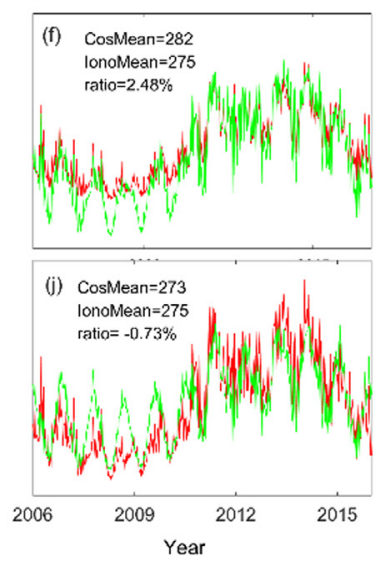
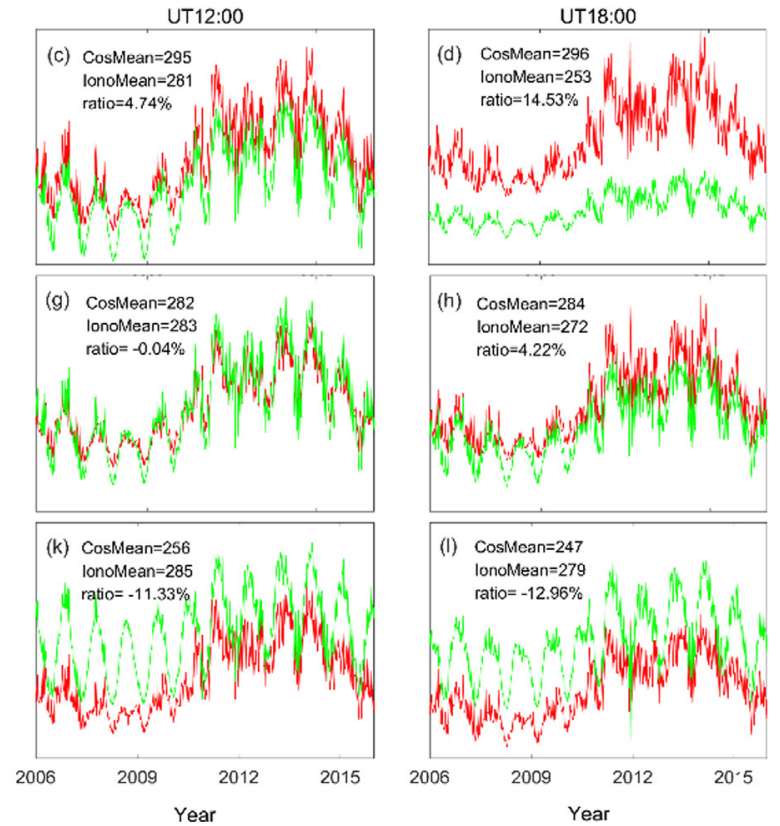

Fig. 6. Same as Fig. 4, but for hmF2.

instruments in different latitudinal zones, to further investigate the global discrepancy between two techniques, the global foF 2 maps simulated by COSPF and IONOPF model at the noon of equinoxes and solstices in the solar moderate year (2013) were compared. Besides, the global foF2 maps estimated by Pushkov Institute of Terrestrial Magnetism, Ionosphere and Radiowave Propagation of the Russian Academy of Sciences (IZMIRAN) were selected as the reference maps. IZMIRAN took the hourly
GIM-TEC maps as an input to the IRI-plas model (International Reference Ionosphere model extended to the plasmasphere) to obtain more realistic scale parameters foF2 and $\mathrm{hmF} 2$, the global foF 2 and $\mathrm{hmF} 2$ maps provided by IZMIRAN can be regarded as new products of GIMTEC (Gulyaeva, 2011). The GIM-TECs were estimated by the dual-frequency observations obtained from hundreds of International GNSS Service (IGS) stations with spherical harmonics, and it has been widely applied in 
the scientific research and practical applications ( $\mathrm{Li}$ et al., 2018a; Li et al., 2017). Therefore, the IZMIRAN maps were available to meet our requirements in this study. The temporal resolutions of three kinds of foF 2 maps were uniform in longitude $\left(5^{\circ}\right)$ and in latitude $\left(2.5^{\circ}\right)$. The global foF 2 maps simulated by COSPF and IONOPF model were compared with the IZMIRAN maps in Fig. 7, and the corresponding ratios of the differences were calculated as follows

$$
\begin{aligned}
& \text { Ratio1 }=\frac{\text { COSMIC }_{\text {map }}-I_{\text {IZMIRAN }} \text { map }}{\text { COSMIC }_{\text {map }}} \\
& \text { Ratio2 }=\frac{\text { IONO }}{\text { map }}-\text { IZMIRAN }_{\text {map }} \\
& \text { IONO }_{\text {map }}
\end{aligned}
$$

where $C O S M I C_{\text {map }}$ and $I O N O_{\text {map }}$ represent the ionospheric maps simulated by the COSPF and IONOPF models respectively.

Fig. 7 showed that the foF 2 values in the Europe-Africa sector were significantly higher than that in other regions at the noon (UT), and the equatorial ionization anomaly (EIA) was also observed in both IZMIRAN and COSMIC maps. Generally, the physical features of COSMIC-foF2 and IONO-foF2 maps agree well with IZMIRAN maps in the low-middle latitude regions, both of them can capture the EIA structure well. Due to the limitation of the asymmetrical distribution of global ionosondes, the simulated performances of the IONOPF model in the polar areas were not satisfied, see the third column in Fig. 7.
The right columns indicated the ratios of the differences between the IZMIRAN's map and the ANN models' maps, it was found that the performance of ANN models was dependent on seasons and geographic latitudes. For season, the ratios of the differences between IZMIRAN's products and ANN models' simulations in the equinoxes were much smaller than that in the solstices. For latitude, the ANN models' performances in the low-middle latitudes were much better than the simulations in the high latitudes. For example, in the summer solstice, see Fig. 7(i), the ratios of the differences between the IZMIRAN's maps and the COSPF's simulations in the low latitudes ranged from -0.2 to 0.2 , while the maximum ratio over the Antarctica exceeded 0.6. Compared with the COSPF model's results, the IONOPF's performances were dissatisfactory in the south polar regions. The amplitude and extent of IONOPF's simulated errors around the Weddell Sea were larger than COSPF significantly. In Fig. 7(j), the extent of large-amplitude simulated errors of IONOPF model was 3-4 times larger than of COSPF. This phenomenon was also observed in the winter solstice, but the highamplitude differences were mainly appeared in the Europe and Greenland. In addition, both COSPF and IONOPF models grossly underestimated foF2 values around Queen Elizabeth Islands, Victoria Island and Beaufort Sea. The maximum amplitude of negative differences exceeded -0.6 .
(a)IZMIRAN_0322_12

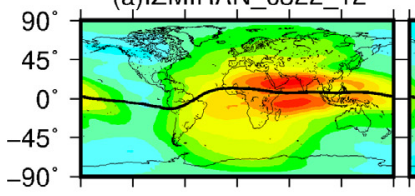

(f)IZMIRAN_0622_12

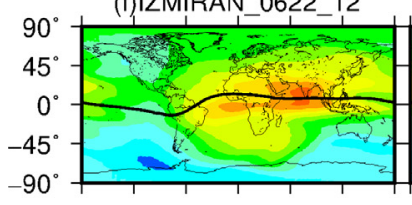

(k)IZMIRAN_0922_12

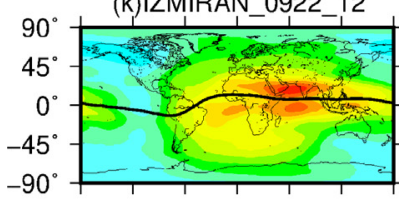

(p)IZMIRAN_1222_12

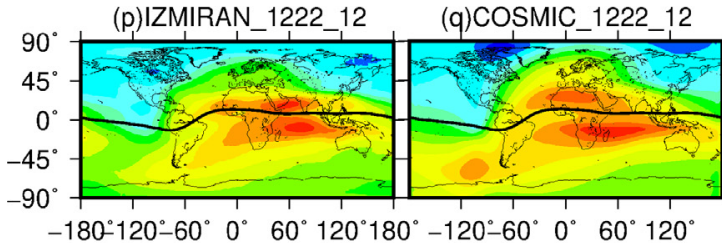

$-180^{\circ} 120^{\circ}-60^{\circ} 0^{\circ} 60^{\circ} 120^{\circ} 180^{\circ}-120^{\circ}-60^{\circ} 0^{\circ} 60^{\circ} 120^{\circ}$

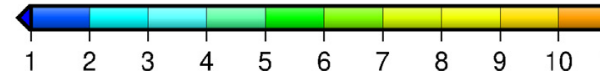

(b)COSMIC_0322_12

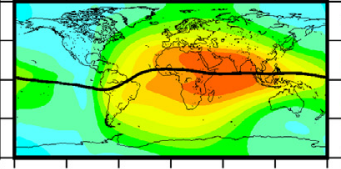

(g)COSMIC_0622_12

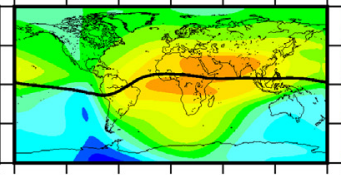

(I)COSMIC_0922_12

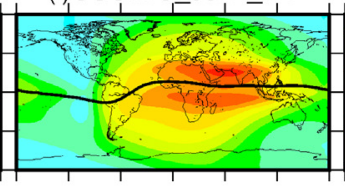

(m)IONO_0922_12

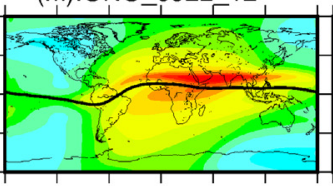

(r) IONO_1222_12

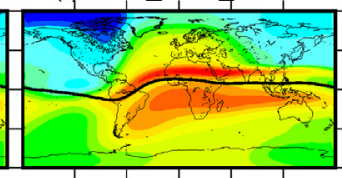

$-120^{\circ}-60^{\circ} 0^{\circ} 60^{\circ} 120^{\circ}$
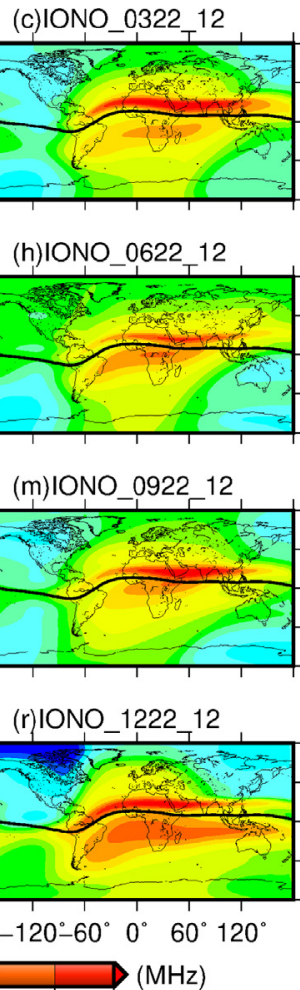

(h)IONO 062212

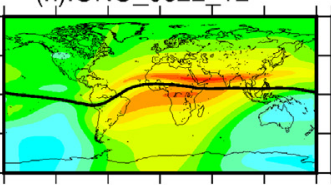

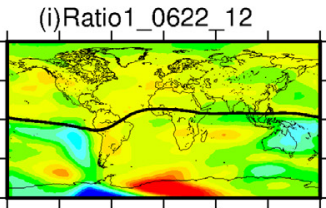

(n)Ratio1_0922_12

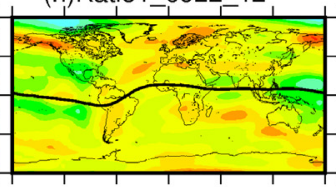

(s)Ratio1_1222_12

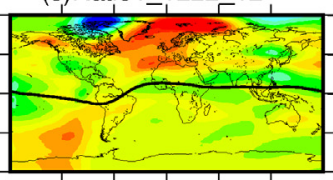

$-120^{\circ}-60^{\circ} 0^{\circ} 60^{\circ} 120^{\circ}-180^{\circ} 120^{\circ}-60^{\circ} 0^{\circ} 60^{\circ} 120^{\circ} 180^{\circ}$

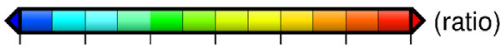

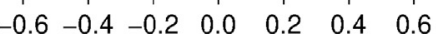

(e)Ratio2_0322_12
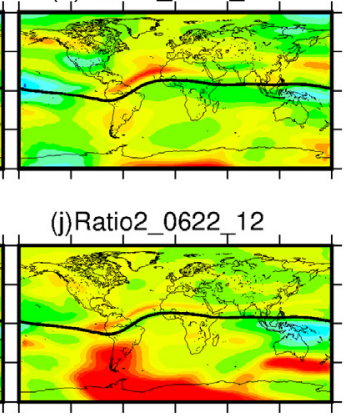

(o)Ratio2_0922_12

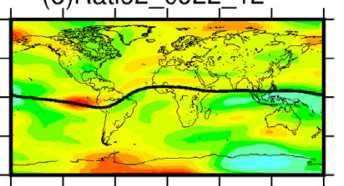

(t) Ratio2_1222 12

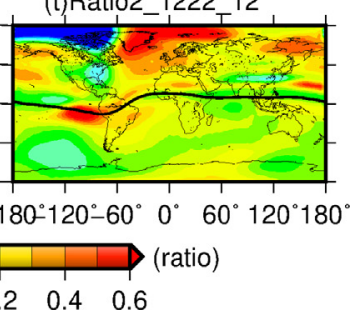

Fig. 7. Comparative results of the global foF 2 maps from the Pushkov Institute of Terrestrial Magnetism, Ionosphere and Radiowave Propagation of the Russian Academy of Sciences (IZMIRAN), COSMIC, and ionosonde in equinoxes and solstices during 2013. The black line signifies the geomagnetic equator. 
To further investigate the discrepancies between ANN models and IZMIRAN maps' dependancy on solar activity, the comparisons were conducted in solar minimum year (2017), as shown in Fig. 8. The figure showed the physical features of global discrepancies in 2017 were consistent with the results in 2013, the simulated performances of the COSPF model were much better than that of the IONOPF model. Compared with 2013, the amplitude of discrepancies in 2017 was smaller within the mean value 0.1 , which indicated the simulated performance of the ANN model was inversely proportional to the degree of solar radiation.

The global hmF2 discrepancies between IZMIRAN, $\mathrm{COSPH}$, and IONOPH were computed at the noon of equinoxes and solstices in 2013, as shown in Fig. 8. From the left column, it was found that the global distribution of the hmF2 reference map at the noon was not consistent with foF2. In the sunlit hemisphere, the hmF2 value around the geomagnetic equator was much larger than that in the higher latitudes; while in the night hemisphere, the high $\mathrm{hmF} 2$ regions gradually moved to polar regions, see Fig. $8(\mathrm{k})$ and (p). The global hmF2 maps simulated by the COSPH model in the panels of the second column agreed well with theIZMIRAN products, but the simulated maps of the IONOPH model in the south polar region was unsatisfactory. The fourth and fifth columns showed the ratio of discrepancies between reference, $\mathrm{COSPH}$ and IONOPF model ranged from -0.2 to 0.2 in the lowmiddle latitudes, but the maximum ratio for the IONOPF model exceeded 0.4 in the Antarctica at the winter solstice. Besides, the discrepancies were dependent on geographic latitude and seasons significantly. For latitude, the simulated maps of COSPF and IONOPF in the low-middle latitudes were better agreed with the reference maps than that in the polar regions, see Fig. 8(i) and (s). For seasons, the amplitudes of discrepancies in the winter were much larger than that in other seasons. For example, the ratios of the simulated errors of the COSPH and IONOPH models in the winter ranged from 0.2 to 0.4 , and the discrepancies covered most of the southern hemisphere.

The discrepancies between IZMIRAN, COSPH, and IONOPH were also analyzed in the solar moderate year (2013) and solar minimum year (2017), as shown in Fig. 9 and Fig. 10, the comparative results in 2017 were consistent with the results in 2013. In 2017, the averaged amplitude of the discrepancies for the COSPH model was smaller than 0.1, it was lower than the averaged amplitude in 2013 obviously, which indicated the performance of the COSPH model in the low-level solar radiation was much better than that in high-level solar radiation environment. Besides, the relationships between the discrepancies and geographic latitude, season in 2017 were different from that in 2013. For example, from the panels of the fourth column, it was found that most of the high discrepancies were distributed in the low latitudes rather than in the south polar region. Furthermore, the amplitude of hmF2 discrepancies in the summer solstice was more remarkable than that in other seasons, see Fig. 9(i) and (j). The two cases
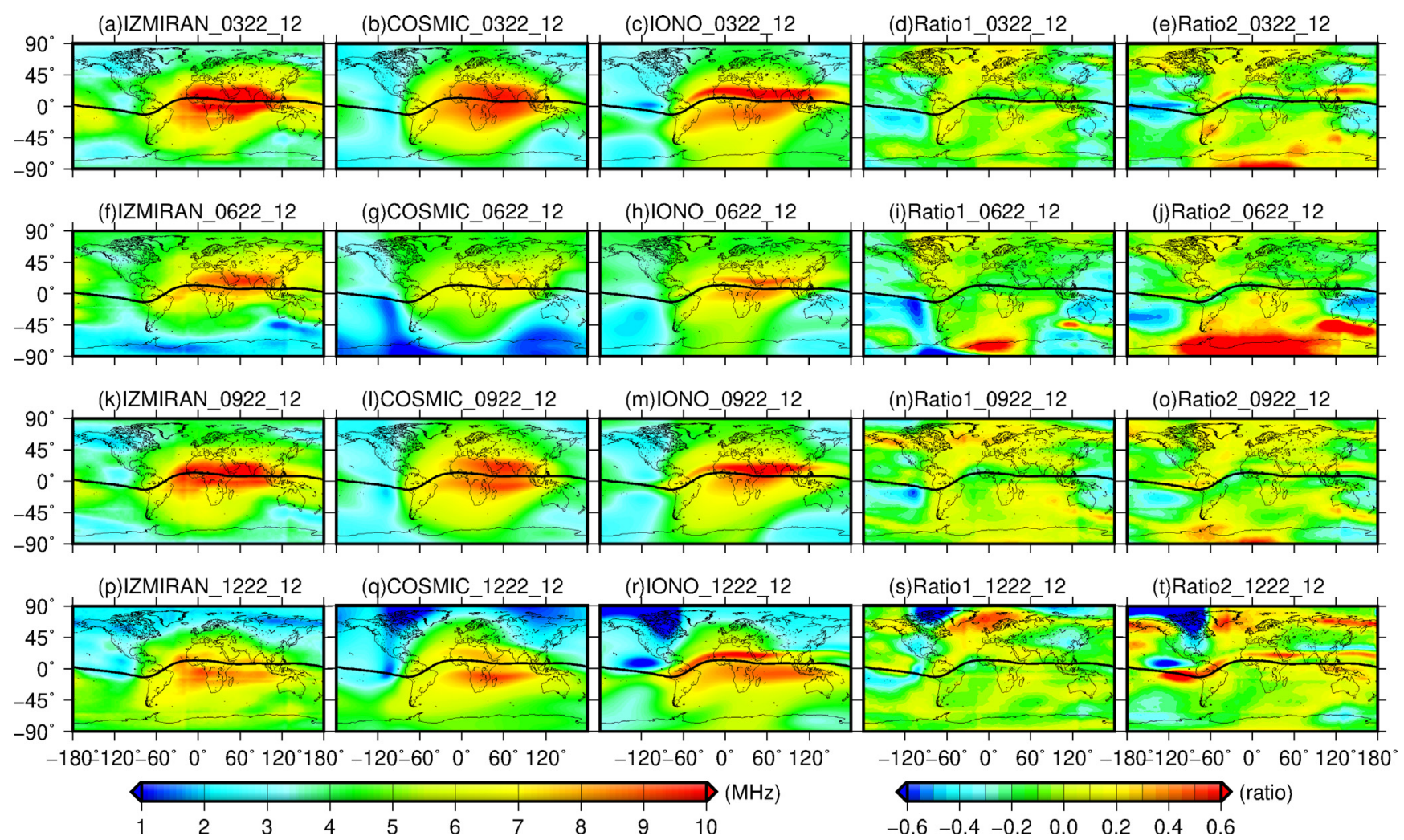

Fig. 8. Same as Fig. 7, but in 2017. 
(a)IZMIRAN_0322_12

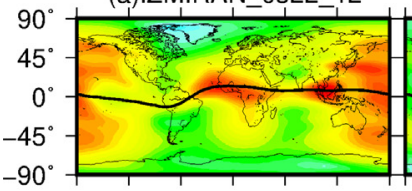

(b)COSMIC_0322_12

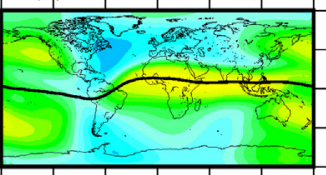

(f)IZMIRAN_0622_12

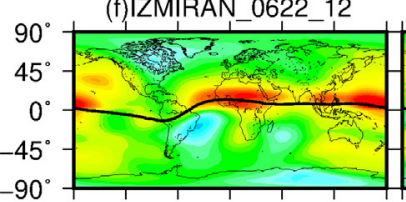

(k)IZMIRAN_0922_12

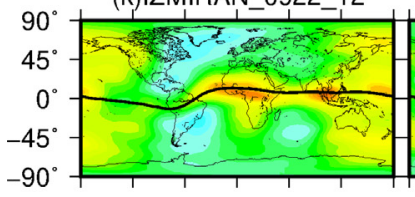

(p)IZMIRAN_1222_12
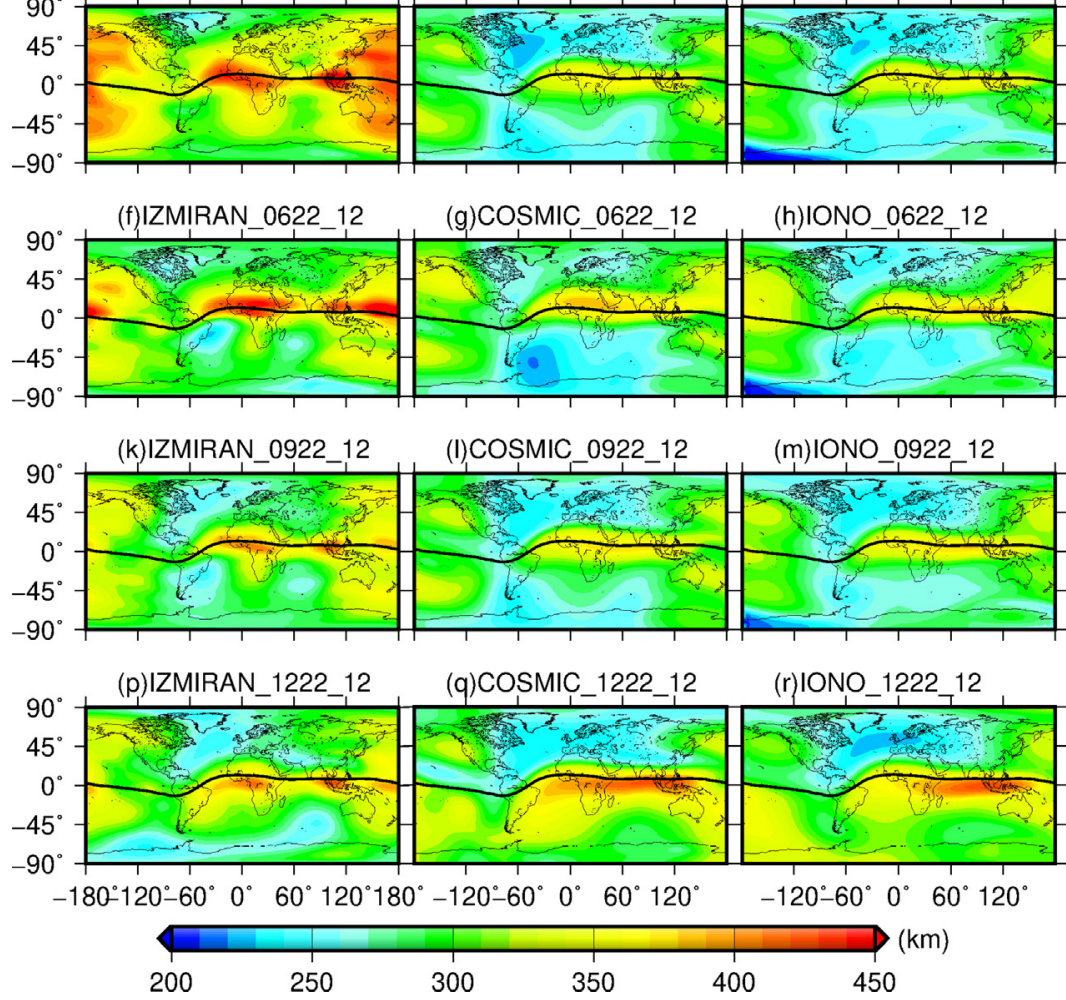

(h)IONO_0622_12

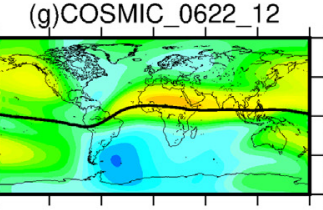

(I)COSMIC_0922_12

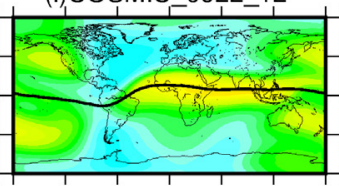

(m)IONO_0922_12

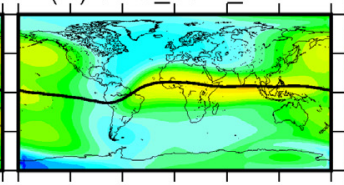

(d)Ratio1_0322_12

(n)Ratio1 092212

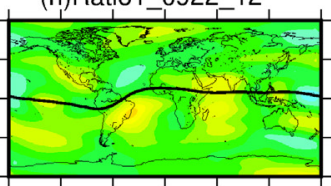

(s)Ratio1 1222 12

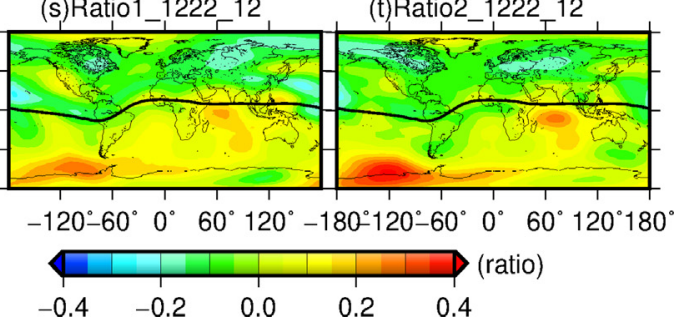

(e)Ratio2_0322_12

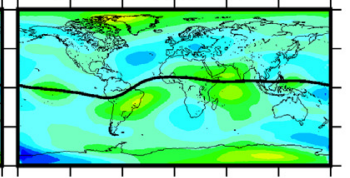

(j)Ratio2_0622_12

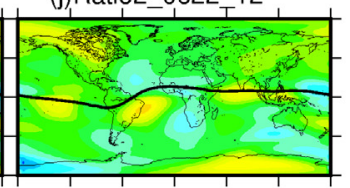

(o)Ratio2_0922_12

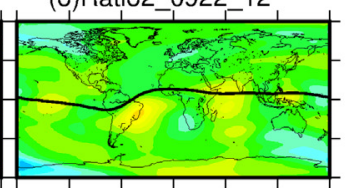

(t)Ratio2 122212

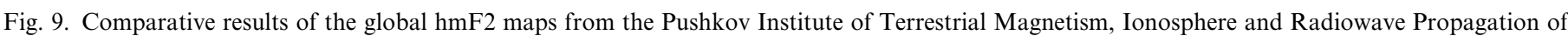

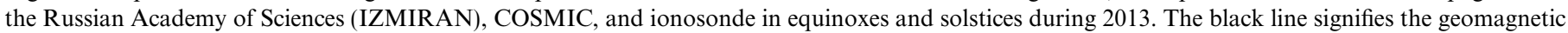
equator.

were not agreed with the results in 2013. It was noted that the blue patchs in the left-bottom corner of Fig. 9(h) and (j) were regarded as invalid value, this simulated errors were also observed in 2013, this phenomenon was attributed to the insufficient ionosonde observations in the Antarctica.

\subsection{Correcting the discrepancies based on ANN}

The results in Sections 3.1 and 3.2 demonstrated that there were unneglectable discrepancies between spaceborne and ground-based techniques, and the discrepancies were dependent on universal time, seasons and geographic latitude significantly. If the remarkable discrepancies weren't corrected in the pre-processing stage of the data assimilation or ionospheric modeling, the assimilative performance or the simulated accuracy of an ionospheric model must be affected seriously. In this study, a new strategy was proposed to correct the discrepancies between different ionospheric detecting techniques, that was taking the parameters of "corrected point" as the input information of COSMIC and ionosonde models based on ANN algorithm, respectively, including time, geographic position, solar-geomagnetic indices, and the discrepancy was computed by the difference between the outputs of COSMIC and ionosonde models, then the final corrected value was estimated by the sum of pre-corrected value and discrepancy. For example, the comparisons in Section 3.2 showed the simulated maps of the COSPF model agreed well with the reference maps, hence in this example, the ionosonde's foF2 data were corrected to the standard of COSMIC technique, the detail processes were as the following four steps.

(1) Step 1: this step is to calculate the simulations of COSPF and IONOPF model using the same inputs. The ten parameters (in Fig. 3) of ionosonde foF2 point $I O N O_{f o F 2}$ are taken as the input information of the COSPF and IONOPF model, respectively.

(2) Step 2: this step is to compute the differences between the simulations of COSPF and IONOPF models. The foF2 values simulated by COSPF and IONOPF model are $C O S P F_{f o F 2}$ and $I O N O P F_{f o F 2}$ respectively, and the difference between $C_{O S P F} F_{f o}$ and $I O N O P F_{f o F 2}$ is computed.

(3) Step 3: this step is to calculate the final corrected value. The sum of the pre-corrected ionosonde foF2 value $I O N O_{f o F 2}$ and the difference is regarded as the final corrected value $C O S M I C_{f o F 2}$ corr .

(4) Step 4: this step is to evaluate the performance of the corrected method. The ten parameters of COSMIC $C_{\text {foF } 2}$ and $C O S M I C_{f o F 2}$ corr are taken as the inputs of COSPF model to simulate the outputs

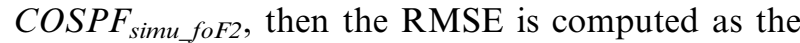
following equation. 
$\begin{array}{lll}\text { (a)IZMIRAN_0322_12 } & \text { (b)COSMIC_0322_12 (c)IONO_0322 12 }\end{array}$

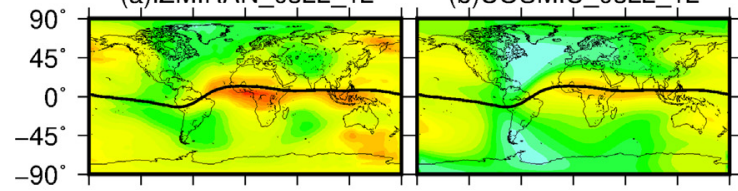

(f)IZMIRAN_0622_12

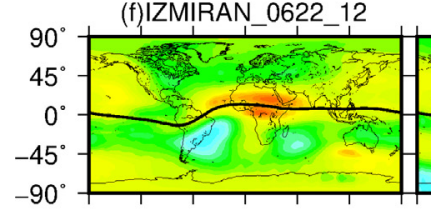

(k)IZMIRAN_0922_12
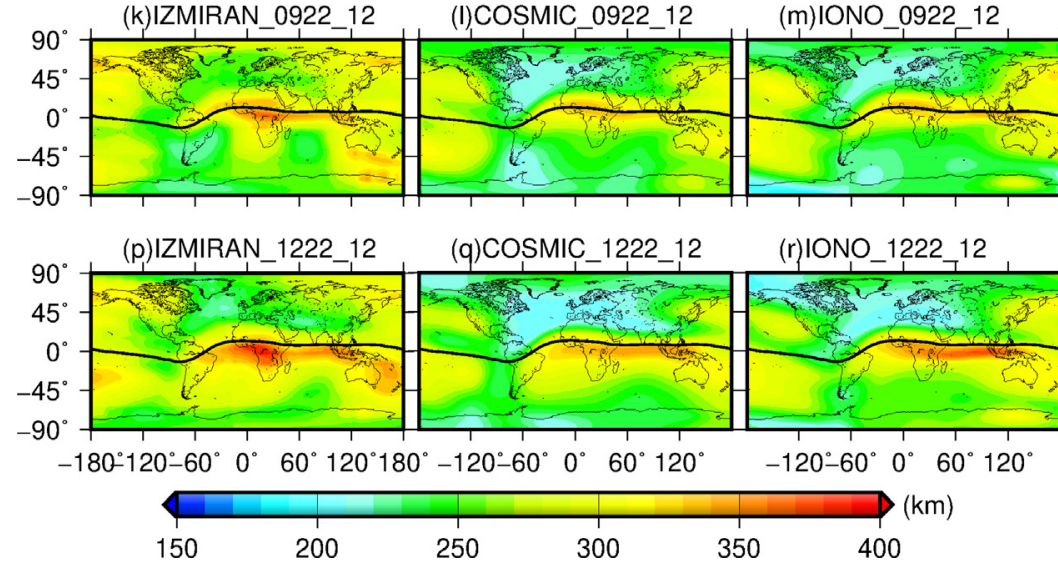

(d)Ratio1_0322_12

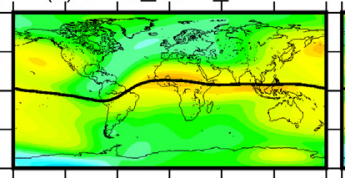

(h)IONO_0622 12

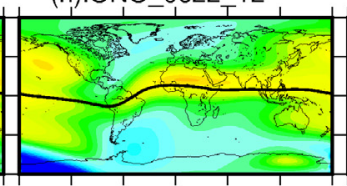

(m)IONO_0922_12

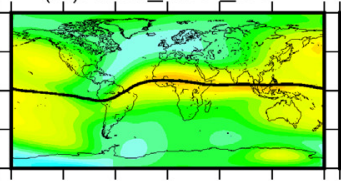

(n)Ratio1_0922_12

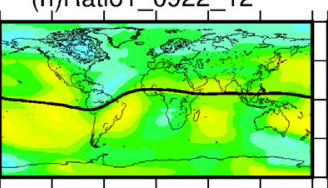

(o)Ratio2_0922_12

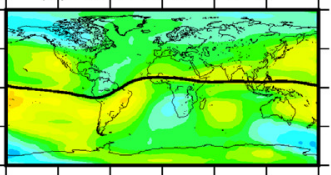

(s)Ratio1_1222_12

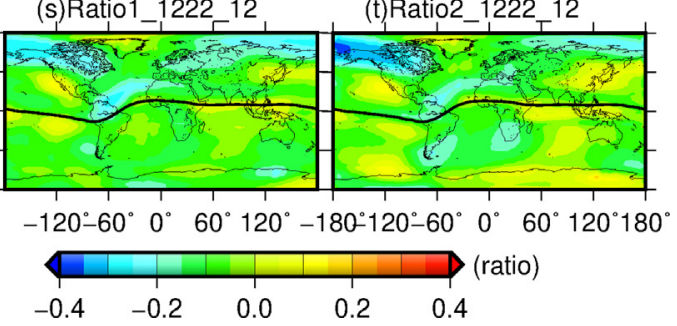

Fig. 10. Same as Fig. 9, but in 2017.

$R M S E(f o F 2)=\sqrt{\frac{1}{m} \sum_{i=1}^{m}\left(\operatorname{COSPF}_{\text {simu }-f o F 2(i)}-\operatorname{COSMIC}_{\text {obs_foF } 2(i)}\right)^{2}}$

where $m$ is the number of ionospheric foF2 points, COSMIC $_{\text {obs } f_{-} F_{2}}$ is a data set of the foF2 measurements derived from COSMIC (COSMIC $\left.\mathrm{CoF}_{\mathrm{f} 2}\right)$ and the corrected foF2 values (COSMIC foF2_corr $_{\text {. }}$ ).

For more details about the correction process, please refer to the equation (5).

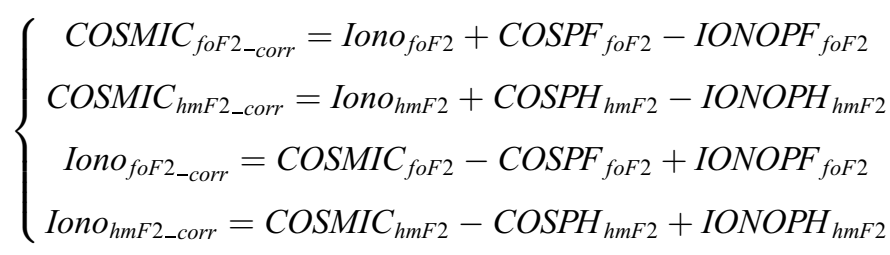

In the study, the data measured by COSMIC and ionosonde was corrected to the opposite standard, respectively. Then the uncorrected dataset and corrected dataset were simulated by the ANN models, respectively. Finally, the RMSE values of four kinds of datasets were estimated, the results were shown in Fig. 11.

In Fig. 11 the cyan bars signified the RMSEs of the uncorrected dataset, and the purple bars signified the RMSEs of the corrected dataset. COSMIC and IONO represented the original ionospheric values measured by COSMIC and ionosonde, and $\operatorname{COSMIC}_{\text {(corr) }}$ and $\operatorname{IONO}_{\text {(corr) }}$ represented the measurements that have been corrected to the opposite standard. For foF2, the RMSE values of datasets in Fig. 11(a) and (c) were estimated by COSPF and IONOPF model; for hmF2, the RMSEs in Fig. 11(b) and (d) were estimated by the COSPH and IONOPH model. Generally, the RMSEs of datasets that have been corrected by the method decreased significantly. In Fig. 11(a), the averaged RMSE of the uncorrected dataset was 1.3 MHz, and the RMSEs during four seasons range from 1.2 $\mathrm{MHz}$ to $1.4 \mathrm{MHz}$, especially in the winter. After the application of this method, the averaged RMSE of the corrected dataset decreased to $0.79 \mathrm{MHz}$, especially in the summer, the averaged RMSE reached to $0.68 \mathrm{MHz}$. Similar to Fig. 11(a), Fig. 11(b) showed the RMSEs of uncorrected hmF2 datasets in four seasons were about 28 $32 \mathrm{~km}$. This method decreased the averaged RMSE from $29.4 \mathrm{~km}$ (uncorrected dataset) to $22.5 \mathrm{~km}$ (corrected dataset) with a maximum ratio of $23.5 \%$. The results in Fig. 11(c) and (d) were consistent with the results in Fig. 11(a) and (b). The averaged RMSE of the corrected foF2 dataset decreased from $1.65 \mathrm{MHz}$ to $1.2 \mathrm{MHz}$ with a ratio of $25 \%$, and this ratio for $\mathrm{hmF} 2$ was $14 \%$, see Fig. 11(d).

The results in Fig. 11 indicated this method based on ANN could improve the accuracy of ionospheric models developed by multiple measurements, the maximum improvement reached $25 \%$. With the application of the method, the averaged RMSEs of multi-source measurements estimated by the COSPF, COSPH, IONOPF, and IONOPH model were $0.79 \mathrm{MHz}, 22.5 \mathrm{~km}, 1.2 \mathrm{MHz}$ and 

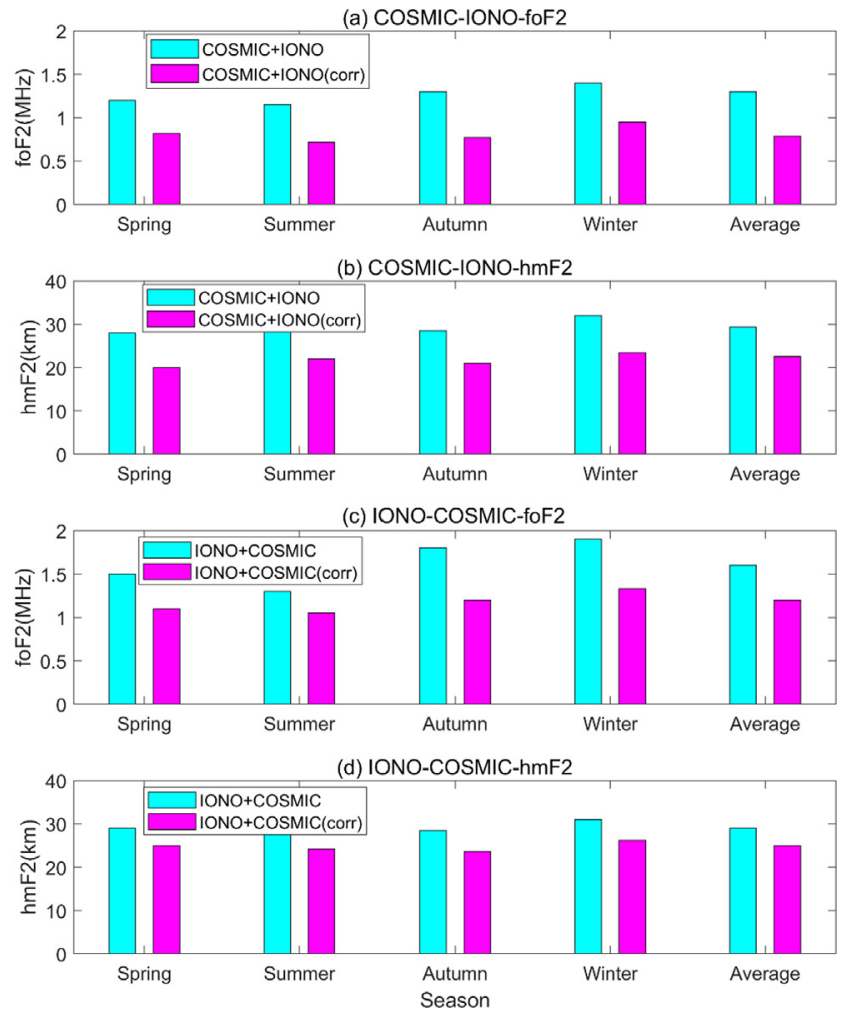

Fig. 11. Comparative results of the RMSEs of four kinds of datasets in four seasons.

$25.02 \mathrm{~km}$, which were slightly larger than the averaged RMSEs of these four models developed by single-source measurements. This phenomenon agreed with the error theory because the discrepancies between multiple instruments couldn't be removed totally (Steane, 1996).

\subsection{Validation of geophysical features of ionospheric model}

Section 3.3 demonstrated the ANN algorithm was available to improve the accuracy of an ionospheric model built by multi-source observations. To further evaluate the physical features of an ionospheric model with the application of this method, the COSMIC's profiles and the corrected ionosonde's data were taken as an example to develop the ionospheric foF2 model using the ANN architecture in Fig. 3. In this study, the prominent ionospheric regional anomalies (Burns et al., 2015; Gowtam and Ram, 2017; Guo et al., 2015; Sai Gowtam and Tulasi Ram, 2017b), including equatorial ionization anomaly, Weddell Sea anomaly, mid-latitude summer nighttime anomaly, and winter anomaly, were simulated by this new model, as shown in Fig. 12.

Fig. 12(a) showed the global ionospheric foF2 map at the noon (local time, LT) in the autumn equinox in 2013, it was found that two clear crests were distributed in two sides of geomagnetic equator with a value of $12 \mathrm{MHz}$, and a trough around the geomagnetic equator with a lower value of $10 \mathrm{MHz}$, which was consistent with the physical characteristics of equatorial ionization anomaly in many previous studies (Appleton, 1946; Balan et al., 2018; Yue et al., 2015). In the middle-high latitudes, the prominent regional anomalies are called as Weddell Sea anomaly and midlatitude summer nighttime anomaly. The Weddell Sea anomaly is characterized by the maximum ionospheric electron density around the Weddell Sea region occurs in nighttime hours (22 LT-04 LT) instead of during daytime hours (10 LT-18 LT) in summer (Lin et al., 2009). Fig. 12(b) showed the global foF2 map at the midnight in the winter solstice, generally, the foF 2 values around EIA were much higher than that in the high-middle latitude regions. However, the ionospheric peak frequencies around the Weddle Sea were larger than that in the low latitudes along the same meridian, which agreed well the nighttime enhancement of ionospheric electron density around Weddell Sea (He et al., 2009; Lin et al., 2009). The ionospheric nighttime enhancement phenomenon in the northern hemisphere is called as midlatitude summer nighttime anomaly (MSNA). Fig. 12(c) showed the difference of global foF2 map between LT22 and LT12 in the summer solstice in 2013, distinct negative differences appeared in the southern hemisphere and the low latitude of the northern hemisphere with a maximum amplitude of $-5 \mathrm{MHz}$. While clear positive differences occurred in the high-middle latitudes of the northern hemisphere, especially in the Siberia and North America, the maximum amplitude exceeded $2 \mathrm{MHz}$, which indicated the ionospheric densities in the high-middle enhanced significantly in the night, the results were in accord with the theory of MSNA (Klimenko et al., 2015; Lin et al., 2010). Winter anomaly is also a wellknown phenomenon produced by the neutral composition asymmetry, the global foF 2 differences at LT12 between the winter solstice and the summer solstice were computed to validate the Winter anomaly, see Fig. 12(d). The results showed that large-scale positive differences occurred in the southern hemisphere and low-middle latitudes of the northern hemisphere, these positive differences in the summer (southern) hemisphere were caused by the enhancement of solar ionization process. In the winter (northern) hemisphere, the intensity of solar radiation was lower than the level in summer, but remarkable positive differences were also observed in the middle latitudes of the northern hemisphere. Therefore it was believed that the positive differences in the winter (northern) hemisphere were resulted from the enhancement of thermosphere neutral composition, which identified with the physical features of Winter anomaly in previous studies (Lee et al., 2011; Torr and Torr, 1973; Yasyukevich et al., 2018). The above discussions conclude that the ionospheric model built by multiple measurements with the application of the new method not only had a higher accuracy, but also had a powerful capability in capturing the ionospheric dynamic physical features. 
(a) Equatorial Anomaly

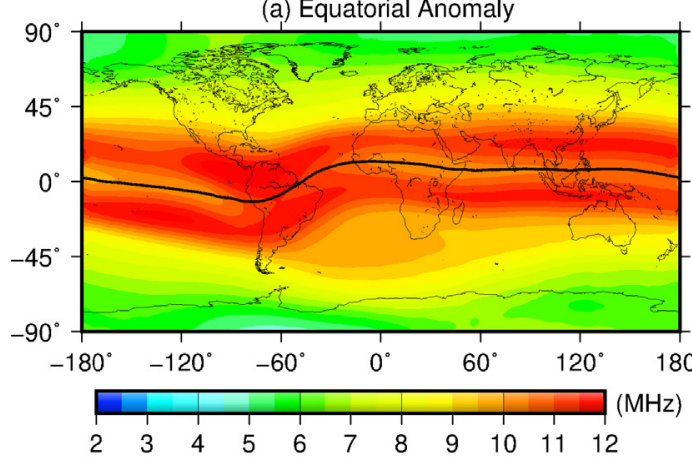

(c) Midlatitude Summer Nighttime Anomaly

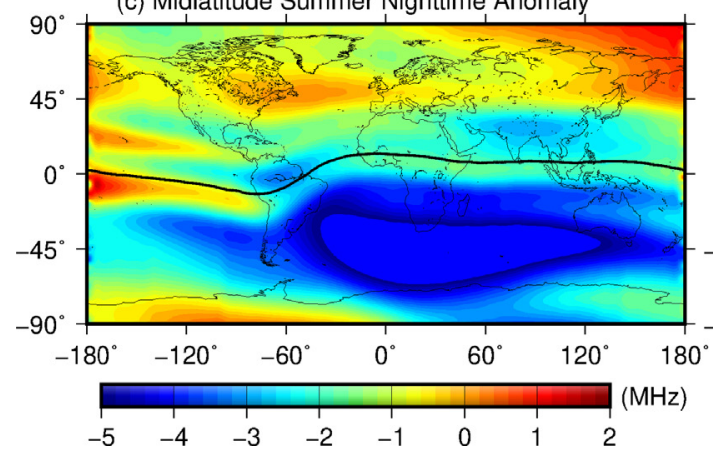

(b) Weddell Sea Anomaly

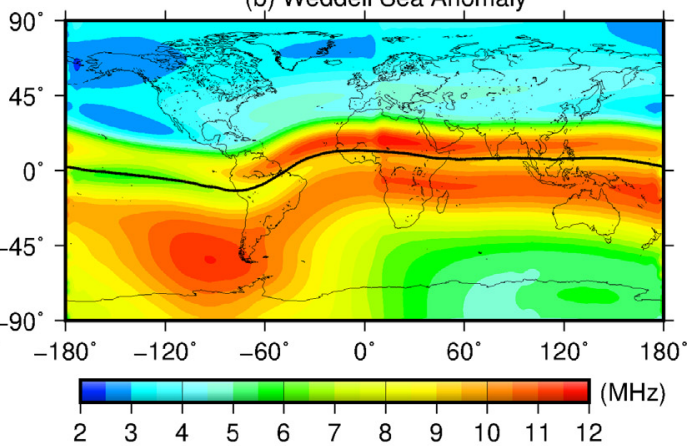

(d) Winter Anomaly

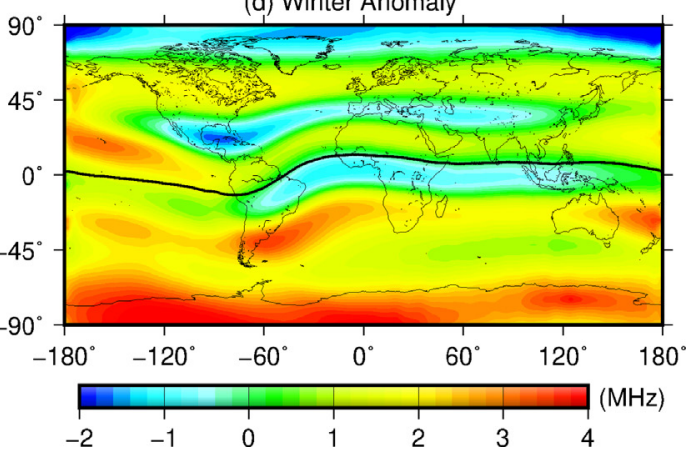

Fig. 12. Four prominent ionospheric regional anomalies simulated by the ANN model developed by corrected datasets.

\section{Conclusions}

In the study, the foF 2 and $\mathrm{hmF} 2$ data measured by COSMIC and ionosonde were utilized to develop the ionospheric models by an ANN method, respectively, namely COSPF, COSPH, IONOPF, and IONOPH. The averaged accuracies of the four models were about $0.58 \mathrm{MHz}$, $19.59 \mathrm{~km}, 0.92 \mathrm{MHz}$ and $23.40 \mathrm{~km}$, respectively. The global foF 2 and hmF2 maps simulated by the ANN models were compared with IZMIRAN products, and the results indicated the global ionospheric maps simulated by ANN models based on COSMIC profiles agreed well with the references. However, the comparisons for the ANN models developed by ionosonde's points were not satisfied. The discrepancies between COSMIC radio occultation and ionosonde were remarkable due to their dependency on universal time, geographic latitude, and seasons. For the peak frequency, the foF2 values measured by COSMIC were generally larger than that of ionosonde, and the amplitude of discrepancies in the nighttime or middle latitudes was maximum within a percent of $25 \%$. For the peak height, the $\mathrm{hmF} 2$ values obtained from COSMIC were usually higher than that of ionosonde in the low latitudes. But in the polar regions, this phenomenon was opposite, the maximum amplitude of differences exceeded $10 \%$ in the midnight and dusk. The high discrepancies may result from the following two factors. First, ionospheric variations in the equator and polar regions are unstable equilibrium. In the equator, the ionospheric mechanism is very complex affected by some dynamic processes, such as fountain effect (Balan and Bailey, 1995), plasma bubbles (McClure et al.,
1977; Smith and Heelis, 2017), etc. The ionospheric instability in the polar region is also remarkable, which is mainly caused by the geomagnetic storms (Shagimuratov et al., 2012), particle precipitation (Frank and Ackerson, 1971), neutral wind (Müller-Wodarg et al., 2012), etc. Second, due to the limitation of land-sea geographic geometry, the ionosonde's measurements that could monitor the ionospheric dynamics over oceans and polar regions are insufficient. The discrepancies between 2017 (solar minimum year) and 2013 (solar moderate year) also concluded that the amplitude of discrepancies was proportional to the intensity of solar radiation. For seasons, the foF2 discrepancies in the solstices were more remarkable than in the equinoxes with a maximum ratio of 0.4 ; the $\mathrm{hmF} 2$ discrepancies in the winter solstice were more significantly.

Considering the discrepancies between space-borne and ground-based observational systems were unneglectable, a new method based on ANN technique was proposed to improve the performance of an ionospheric model built by multiple measurements. The results indicated that the accuracy of an ionospheric model developed by the multi-source observations with the application of this method improved about $14-25 \%$. For example, the averaged RMSE of a foF 2 dataset corrected by the method decreased from $1.3 \mathrm{MHz}$ to $0.79 \mathrm{MHz}$; the averaged RMSE of a hmF2 dataset corrected by the method decreased from $29.4 \mathrm{~km}$ to $22.5 \mathrm{~km}$. Besides, the measurements of COSMIC and ionosonde with the application of this method were used to develop a new global ionospheric foF 2 model, this model not only had a higher accuracy but also had a powerful capability in capturing the ionospheric dynamic 
physical features, including EIA, Weddell Sea anomaly, MSNA, and Winter anomaly.

Finally, it should be noted that the dataset with the application of the method still contained discrepancies, because the simulated errors of ANN model cannot be removed totally. The sum RMSEs of the COSPF and IONOPF model was $1.5 \mathrm{MHz}$, the sum RMSEs of the COSPH and IONOPH model was $43 \mathrm{~km}$. However, in Figs. 6-9, the magnitudes of some regional discrepancies were much larger than the sum RMSEs, especially in the equator and polar regions. Therefore, it was believed that the exceeded discrepancies were attributed to the instrumental bias of different observational systems. In conclusion, the new method based on ANN technique is effective to improve the performance of ionospheric models, not only in the accuracy but also in physical features. However, the proposed ANN method is only suitable to correct the two-dimensional discrepancies (foF2 and $\mathrm{hmF} 2$ ) between the long-term GNSS radio occultation profiles and ground-based GIRO (Global Ionospheric Radio Observatory) observations. The successful performance of the method indicates the ANN technique maybe also a potential tool in developing a complete three-dimensional ionospheric model by assimilating the electron density profiles derived from multiple GNSS-RO missions (COSMIC, GRACE, FY-3C, etc.), ground-based Digisondes and, if available, topside sounders. This would make a more important role in the applications of satellite communication, navigational positioning and space weather awareness.

\section{Declaration of Competing Interest}

The authors declare that they have no known competing financial interests or personal relationships that could have appeared to influence the work reported in this paper.

\section{Acknowledgment}

The authors greatly appreciate the financial support from the National Natural Science Foundations of China (Grant No. 41730109. 41870404), the Open Fund of Key Laboratory for Synergistic Prevention of Water and Soil Environmental Pollution (Grant No. KLSPWSEP-A06), the Project funded by China Postdoctoral Science Foundation (Grant No. 2020M671645), the Fundamental Research Funds for the Central Universities (Grant No. 2020QN31), A Project Funded by the Priority Academic Program Development of Jiangsu Higher Education Institutions (Surveying and Mapping). We would like to acknowledge the support of the Jiangsu Dual Creative Talents and Jiangsu Dual Creative Teams Programme Projects awarded in 2017 and the Xuzhou Key Project (KC19111). We are very grateful to UCAR community programs for providing COSMIC data, the Lowell GIRO Data Center for providing Ionosonde data, the GSFC for providing solar-magnetic indices, the IZMIRAN for providing global foF2 and hmF2 maps.

\section{References}

Appleton, E.V., 1946. Two anomalies in the ionosphere 691-691. Nature 157 (3995). https://doi.org/10.1038/157691a0.

Balan, N., Bailey, G., 1995. Equatorial plasma fountain and its effects: Possibility of an additional layer. J. Geophys. Res. Space Phys. 100 (A11), 21421-21432. https://doi.org/10.1029/95JA01555.

Balan, N., Souza, J., Bailey, G., 2018. Recent developments in the understanding of equatorial ionization anomaly: A review. J. Atmos. Sol. Terr. Phys. 171, 3-11. https://doi.org/10.1016/j.jastp.2017.06.020.

Bauer, P., Radnóti, G., Healy, S., Cardinali, C., 2014. GNSS radio occultation constellation observing system experiments. Mon. Weather Rev. 142 (2), 555-572. https://doi.org/10.1175/MWR-D-13-00130.1.

Bilitza, D., Reinisch, B.W., Radicella, S.M., Pulinets, S., Gulyaeva, T., Triskova, L., 2006. Improvements of the International Reference Ionosphere model for the topside electron density profile. Radio Sci. 41 (5). https://doi.org/10.1029/2005RS003370.

Brum, C.G.M., Rodrigues, F.d.S., Dos Santos, P.T., et al., 2011. A modeling study of foF2 and hmF2 parameters measured by the Arecibo incoherent scatter radar and comparison with IRI model predictions for solar cycles 21, 22, and 23. J. Geophys. Res. Space Phys. 116 (A3). https://doi.org/10.1029/2010JA015727.

Burns, A.G., Solomon, S.C., Wang, W., et al., 2015. Explaining solar cycle effects on composition as it relates to the winter anomaly. J. Geophys. Res. Space Phys. 120 (7), 5890-5898. https://doi.org/10.1002/ 2015 ja021220.

Chu, Y.-H., Su, C.-L., Ko, H.-T., 2010. A global survey of COSMIC ionospheric peak electron density and its height: A comparison with ground-based ionosonde measurements. Adv. Space Res. 46 (4), $431-$ 439. https://doi.org/10.1016/j.asr.2009.10.014.

Ely, C., Batista, I., Abdu, M., 2012. Radio occultation electron density profiles from the FORMOSAT-3/COSMIC satellites over the Brazilian region: A comparison with Digisonde data. Adv. Space Res. 49 (11), 1553-1562. https://doi.org/10.1016/j.asr.2011.12.029.

Frank, L.A., Ackerson, K.L., 1971. Observations of charged particle precipitation into the auroral zone. J. Geophys. Res. 76 (16), 3612 3643. https://doi.org/10.1029/JA076i016p03612.

Gowtam, V.S., Ram, S.T., 2017. Ionospheric winter anomaly and annual anomaly observed from Formosat-3/COSMIC Radio Occultation observations during the ascending phase of solar cycle 24. Adv. Space Res. 60 (8), 1585-1593. https://doi.org/10.1016/j.asr.2017.03.017.

Gowtam, V.S., Tulasi Ram, S., Reinisch, B., Prajapati, A., 2019. A new artificial neural network-based global three-dimensional ionospheric model (ANNIM-3D) using long-term ionospheric observations: Preliminary results. J. Geophys. Res. Space Phys. 124 (6), 4639-4657. https://doi.org/10.1029/2019JA026540.

Gulyaeva, T., 2011. Storm time behavior of topside scale height inferred from the ionosphere-plasmasphere model driven by the F2 layer peak and GPS-TEC observations. Adv. Space Res. 47 (6), 913-920. https:// doi.org/10.1016/j.asr.2010.10.025.

Guo, J., Li, W., Liu, X., Kong, Q., Zhao, C., Guo, B., . Temporal-spatial variation of global GPS-derived total electron content, 1999-2013. PLoS ONE 10 (7). https://doi.org/10.1371/journal.pone.0133378.

Guo, J., Shi, K., Liu, X., Sun, Y., Li, W., Kong, Q., 2019. Singular spectrum analysis of ionospheric anomalies preceding great earthquakes: Case studies of Kaikoura and Fukushima earthquakes. J. Geodyn. 1241-13. https://doi.org/10.1016/j.jog.2019.01.005.

He, M., Liu, L., Wan, W., et al., 2009. A study of the Weddell Sea Anomaly observed by FORMOSAT-3/COSMIC. J. Geophys. Res. Space Phys. 114 (A12). https://doi.org/10.1029/2009JA014175.

Hu, L., Ning, B., Liu, L., Zhao, B., Chen, Y., Li, G., 2014. Comparison between ionospheric peak parameters retrieved from COSMIC measurement and ionosonde observation over Sanya. Adv. Space Res. 54 (6), 929-938. https://doi.org/10.1016/j.asr.2014.05.012. 
Klimenko, M., Klimenko, V., Ratovsky, K., et al., 2015. Mid-latitude Summer Evening Anomaly (MSEA) in F2 layer electron density and Total Electron Content at solar minimum. Adv. Space Res. 56 (9), 1951-1960. https://doi.org/10.1016/j.asr.2015.07.019.

Krankowski, A., Zakharenkova, I., Krypiak-Gregorczyk, A., Shagimuratov, I.I., Wielgosz, P., 2011. Ionospheric electron density observed by FORMOSAT-3/COSMIC over the European region and validated by ionosonde data. J. Geod. 85 (12), 949-964. https://doi.org/10.1007/ s00190-011-0481-z.

Lee, W., Kil, H., Kwak, Y.S., Wu, Q., Cho, S., Park, J., 2011. The winter anomaly in the middle-latitude $\mathrm{F}$ region during the solar minimum period observed by the Constellation Observing System for Meteorology, Ionosphere, and Climate. J. Geophys. Res. Space Phys. 116 (A2). https://doi.org/10.1029/2010JA015815.

Lei, J., Syndergaard, S., Burns, A.G., et al., 2007. Comparison of COSMIC ionospheric measurements with ground-based observations and model predictions: Preliminary results. J. Geophys. Res. Space Phys. 112 (A7). https://doi.org/10.1029/2006JA012240.

Li, W., Yue, J., Guo, J., et al., 2018a. Statistical seismo-ionospheric precursors of M7. 0+ earthquakes in Circum-Pacific seismic belt by GPS TEC measurements. Adv. Space Res. 61 (5), 1206-1219. https:// doi.org/10.1016/j.asr.2017.12.013.

Li, W., Yue, J., Wu, S., et al., 2018b. Ionospheric responses to typhoons in Australia during 2005-2014 using GNSS and FORMOSAT-3/COSMIC measurements. GPS Solut. 22 (3), 61. https://doi.org/10.1007/ s10291-018-0722-1.

Li, W., Yue, J., Yang, Y., He, C., Hu, A., Zhang, K., 2018c. Ionospheric and thermospheric responses to the recent strong solar flares on 6 september 2017. J. Geophys. Res. Space Phys. 123 (10), 8865-8883. https://doi.org/10.1029/2018JA025700.

Li, W., Yue, J., Yang, Y., et al., 2017. Analysis of ionospheric disturbances associated with powerful cyclones in East Asia and North America. J. Atmos. Sol. Terr. Phys. 16143-54. https://doi.org/ 10.1016/j.jastp.2017.06.012.

Li, W., Zhao, D., He, C., Hu, A., Zhang, K., 2020. Advanced machine learning optimized by the genetic algorithm in ionospheric models using long-term multi-instrument observations. Remote Sens. 12 (5), 866. https://doi.org/10.3390/rs12050866.

Li, Z., Yuan, Y., Wang, N., Hernandez-Pajares, M., Huo, X., 2015. SHPTS: towards a new method for generating precise global ionospheric TEC map based on spherical harmonic and generalized trigonometric series functions. J. Geod. 89 (4), 331-345. https://doi. org/10.1007/s00190-014-0778-9.

Lin, C.-H., Liu, C.-H., Liu, J.-Y., Chen, C.-H., Burns, A.G., Wang, W., 2010. Midlatitude summer nighttime anomaly of the ionospheric electron density observed by FORMOSAT-3/COSMIC. J. Geophys. Res. Space Phys. 115 (A3). https://doi.org/10.1029/2009JA014084.

Lin, C.-H., Liu, J.-Y., Cheng, C.-Z., et al., 2009. Three-dimensional ionospheric electron density structure of the Weddell Sea Anomaly. J. Geophys. Res. Space Phys. 114 (A2). https://doi.org/10.1029/ 2008JA013455.

McClure, J., Hanson, W., Hoffman, J., 1977. Plasma bubbles and irregularities in the equatorial ionosphere. J. Geophys. Res. 82 (19), 2650-2656. https://doi.org/10.1029/JA082i019p02650.

McCulloch, W.S., Pitts, W., 1943. A logical calculus of the ideas immanent in nervous activity. Bull. Math. Biophys. 5 (4), 115-133. https://doi.org/10.1007/BF02478259.

McNamara, L.F., Thompson, D.C., 2015. Validation of COSMIC values of foF2 and M (3000) F2 using ground-based ionosondes. Adv. Space Res. 55 (1), 163-169. https://doi.org/10.1016/j.asr.2014.07.015.

Müller-Wodarg, I., Moore, L., Galand, M., Miller, S., Mendillo, M., 2012. Magnetosphere-atmosphere coupling at Saturn: 1-Response of thermosphere and ionosphere to steady state polar forcing. Icarus 221 (2), 481-494. https://doi.org/10.1016/j.icarus.2012.08.034.

Okoh, D., Seemala, G., Rabiu, B., et al., 2019. A neural network based ionospheric model over Africa from COSMIC and ground GPS observations. J. Geophys. Res. Space Phys. https://doi.org/10.1029/ 2019JA027065.
Potula, B.S., Chu, Y.H., Uma, G., Hsia, H.P., Wu, K.H., 2011. A global comparative study on the ionospheric measurements between COSMIC radio occultation technique and IRI model. J. Geophys. Res. Space Phys. 116 (A2). https://doi.org/10.1029/2010JA015814.

Ram, S.T., Su, S.-Y., Tsai, L.-C., Liu, C.H., 2016. A self-contained GIMaided Abel retrieval method to improve GNSS-Radio Occultation retrieved electron density profiles. GPS Solutions 20 (4), 825-836. https://doi.org/10.1007/s10291-015-0491-z.

Rishbeth, H., Müller-Wodarg, I., Zou, L., et al., 2000. Annual and semiannual variations in the ionospheric F2-layer: II. Physical discussion. In: Annales Geophysicae. Springer, pp. 945-956.

Sai Gowtam, V., Tulasi Ram, S., 2017a. An artificial neural networkbased ionospheric model to predict $\mathrm{NmF} 2$ and $\mathrm{hmF} 2$ using long-term data set of FORMOSAT-3/COSMIC radio occultation observations: preliminary results. J. Geophys. Res. Space Phys. 122 (11), 1174311755. https://doi.org/10.1002/2017JA024795.

Sai Gowtam, V., Tulasi Ram, S., 2017b. Ionospheric annual anomalyNew insights to the physical mechanisms. J. Geophys. Res. Space Phys. 122 (8), 8816-8830. https://doi.org/10.1002/2017JA024170.

Shagimuratov, I., Krankowski, A., Ephishov, I., Cherniak, Y., Wielgosz, P., Zakharenkova, I., 2012. High latitude TEC fluctuations and irregularity oval during geomagnetic storms. Earth Planets Space 64 (6), 521-529. https://doi.org/10.5047/eps.2011.10.015.

Smith, J., Heelis, R.A., 2017. Equatorial plasma bubbles: Variations of occurrence and spatial scale in local time, longitude, season, and solar activity. J. Geophys. Res. Space Phys. 122 (5), 5743-5755. https://doi. org/10.1002/2017JA024128.

Song, R., Zhang, X., Zhou, C., Liu, J., He, J., 2018. Predicting TEC in China based on the neural networks optimized by genetic algorithm. Adv. Space Res. 62 (4), 745-759. https://doi.org/10.1016/j. asr.2018.03.043.

Specht, D.F., 1990. Probabilistic neural networks. Neural Netw. 3 (1), 109-118. https://doi.org/10.1016/0893-6080(90)90049-Q.

Steane, A.M., 1996. Error correcting codes in quantum theory. Phys. Rev. Lett. 77 (5), 793. https://doi.org/10.1103/PhysRevLett.77.793.

Sun, L., Zhao, B., Yue, X.A., Mao, T., 2014. Comparison between ionospheric character parameters retrieved from FORMOSAT3 measurement and ionosonde observation over China. Chin. J. Geophys., $573625-573632$

Themens, D.R., Jayachandran, P., Galkin, I., Hall, C., 2017. The empirical Canadian high arctic ionospheric model (E-CHAIM): NmF2 and hmF2. J. Geophys. Res. Space Phys. 122 (8), 9015-9031. https://doi.org/10.1002/2017JA024398.

Torr, M.R., Torr, D., 1973. The seasonal behaviour of the F2-layer of the ionosphere. J. Atmos. Terr. Phys. 35 (12), 2237-2251. https://doi.org/ 10.1016/0021-9169(73)90140-2.

Tulasi Ram, S., Sai Gowtam, V., Mitra, A., Reinisch, B., 2018. The improved two-dimensional artificial neural network-based ionospheric model (ANNIM). J. Geophys. Res. Space Phys. 123 (7), 5807-5820. https://doi.org/10.1029/2018JA025559.

Widrow, B., Hoff, M.E., 1960. Adaptive Switching Circuits. Stanford Univ Ca Stanford Electronics Labs.

Yasyukevich, Y.V., Yasyukevich, A.S., Ratovsky, K.G., Klimenko, M.V., Klimenko, V.V., Chirik, N.V., 2018. Winter anomaly in NmF2 and TEC: when and where it can occur. J. Space Weather Space Clim. 8 (A45). https://doi.org/10.1051/swsc/2018036.

Yue, X., Schreiner, W.S., Kuo, Y.-H., Lei, J., 2015. Ionosphere equatorial ionization anomaly observed by GPS radio occultations during 2006 2014. J. Atmos. Sol. Terr. Phys. 129, 30-40. https://doi.org/10.1016/ j.jastp.2015.04.004.

Yue, X., Schreiner, W.S., Pedatella, N., et al., 2014. Space weather observations by GNSS radio occultation: From FORMOSAT-3/ COSMIC to FORMOSAT-7/COSMIC-2. Space Weather 12 (11), 616-621. https://doi.org/10.1002/2014SW001133.

Zhang, M.-L., Liu, L., Wan, W., Ning, B., 2014. An update global model of $\mathrm{hmF} 2$ from values estimated from ionosonde and COSMIC/ FORMOSAT-3 radio occultation. Adv. Space Res. 53 (3), 395-402. https://doi.org/10.1016/j.asr.2013.11.053. 